\title{
Consensus on hemophilia in Mexico
}

José L. López-Arroyo', Juan M. Pérez-Zúñiga², Laura E. Merino-Pasaye², Azucena Saavedra-González², Luisa María Alcivar-Cedeño², José Luis Álvarez-Vera², Irene Anaya-Cuellar', Luara L. Arana-Luna², David Ávila-Castro², Ramón A. Bates-Martín², Gabriela Cesarman-Maus', Lénica A. Chávez-Aguilar², José A. de la Peña-Celaya², María E. Espitia-Ríos², Patricia Estrada-Domínguez², Denisse FermínCaminero², Willy Flores-Patricio ${ }^{6}$, Jaime García Chávez ${ }^{7}$, María T. García-Lee ${ }^{8}$, Ma. del Carmen González-Pérez9 , Ma. del Carmen González-Rubio², Ma. Guadalupe González-Villareal10, Fabiola Ramírez-Moreno ${ }^{11}$, Ana K. Hernández-Colin², Eleazar Hernández-Ruiz², Wilfrido Herrera-Olivares'2, Faustino Leyto-Cruz ${ }^{13}$, Sergio Loera-Fragoso ${ }^{14}$, Annel Martínez-Ríos ${ }^{15}$, María R. Miranda-Madrazo ${ }^{2}$, Alba Morales-Hernández ${ }^{2}$, Lorena Nava-Villegas ${ }^{2}$, Juan J. Orellana-Garibay ${ }^{16}$, Orlando G. Palma-Moreno², Eugenia P. Paredes-Lozano ${ }^{17}$, Paula Peña-Alcántara², Uendy Pérez-Lozano ${ }^{18}$, Yayra M. Pichardo-Cepín ${ }^{5}$, Ana Carolina Reynoso-Pérez ${ }^{2}$, Mishel Rodríguez-Serna ${ }^{19}$, Flavio Rojas-Castillejos ${ }^{2}$, Hilda RomeroRodelo ${ }^{20}$, Josué I. Ruíz-Contreras ${ }^{21}$, Adela Segura-García², Karina Silva-Vera ${ }^{22}$, Paulina M. SotoCisneros $^{2}$, Ana L. Tapia-Enríquez ${ }^{4}$, Martha G. Tavera-Rodríguez ${ }^{23}$, Óscar Teomitzi-Sánchez², Fredy Tepepa-Flores ${ }^{2}$, María D. Valencia-Rivas ${ }^{15}$, Teresa Valle-Cárdenas², Ana Varela-Constantino ${ }^{24}$, Adrián Javier-Morales ${ }^{25}$, Mario A. Martínez-Ramírez ${ }^{26}$, Sergio Tena-Cano ${ }^{27}$, Ricardo Terrazas-Marín ${ }^{28}$, Shendel P. Vilchis-González², Atenas Villela-Peña ${ }^{2}$, Verónica Mena-Zepeda ${ }^{29}$ y Martha Alvarado Ibarra *

${ }^{1}$ Hematology department, Hospital General "B" del ISSSTE, Ciudad Juárez, Chih.; ${ }^{2}$ Hematology department, Centro Médico Nacional 20 de Noviembre, ISSSTE, Mexico City; ${ }^{3}$ Hematology department, Hospital Bicentenario de la Independencia, ISSSTE, Edo. Méx.; ${ }^{4} H e m a t o l o g y$ department, Hospital General ISSSTE Presidente Lázaro Cárdenas, Chihuahua, Chih.; ${ }^{5}$ Hematology department, Unidad de Hemostasia y Trombosis, Instituto Nacional de Cancerología, Mexico City; ${ }^{6}$ Hematology department, Hospital General ISSSTE Cuernavaca, Mor.; ${ }^{7}$ Hematology department, UMAE, Hospital de Especialidades del Centro Médico Nacional La Raza, Mexico City; ${ }^{8}$ Hematology department, Hospital General

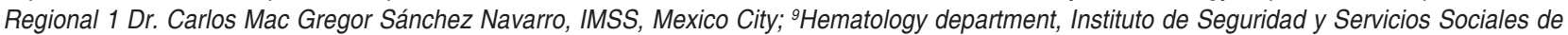
Ios Trabajadores del Estado de Sonora, ISSSTESON, Hermosillo, Son.; ${ }^{10} \mathrm{Hematology}$ department, Unidad Médica de Alta Especialidad N. ${ }^{\circ} 25$ IMSS, Monterrey, N.L.; ${ }^{11}$ Hematology department, Hospital Regional Presidente Juárez, ISSSTE, Oaxaca, Oax.; ${ }^{12}$ Hematology department, Hospital Regional de Puebla, ISSSTE, Puebla, Pue.; ${ }^{13} \mathrm{Hematology}$ department, Hospital Licenciado Adolfo López Mateos, ISSSTE, Mexico City; ${ }^{14} \mathrm{Hematology}$ department, Hospital Doctor Santiago Ramón y Cajal ISSSTE, Durango, Dgo.; ${ }^{15}$ Hematology department, Hospital Regional General Ignacio Zaragoza, ISSSTE, Mexico City; ${ }^{16} \mathrm{Hematology}$ department, Hospital de Alta Especialidad Centenario de la Revolución Mexicana ISSSTE, Cuernavaca, Mor.; ${ }^{17} \mathrm{Hematology}$ department, Hospital Regional $10^{\circ}$ de Octubre, ISSSTE, Mexico City; ${ }^{18} \mathrm{Hematology}$ department, UMAE IMSS, Puebla, Pue.; ${ }^{19}$ Infrastructure Subdirectorate, ISSSTE, Ciudad de México; ${ }^{20}$ Hematology department, Hospital General Fray Junipero Serra ISSSTE, Tijuana, B.C.; ${ }^{21}$ Internal Medicine service, Hospital Regional de Alta Especialidad, Oaxaca, Oax.; ${ }^{22}$ Servicio de Hematología, Hospital General ISSSTE, Tampico, Tamps.; ${ }^{23} \mathrm{Hematology} \mathrm{department,} \mathrm{Instituto} \mathrm{Nacional} \mathrm{de} \mathrm{Pediatría,} \mathrm{Mexico} \mathrm{City;}{ }^{24} \mathrm{Hematology}$ department, Hospital Médica Sur, Mexico City; ${ }^{25} \mathrm{Hematology}$ department, Hospital Regional Mérida, ISSSTE, Mérida, Yuc.; ${ }^{26} \mathrm{Hematology}$ department, Hospital Regional B ISSSTE, Veracruz, Ver.; ${ }^{27} \mathrm{Hematology}$ department, Star Médica Centro, Mexico City; ${ }^{28} \mathrm{Hematology}$ department, Hospital Ángeles Lomas, Mexico City; ${ }^{29}$ Hematology department, Medicina Hematológica Privada, Mexico City. Mexico.

Correspondence:

*Martha Alvarado-Ibarra

E-mail: normoblasto@gmail.com
Gac Med Mex. 2021;157(Supl 1):S1-S35

Contents available at PubMed
Date of reception: $28-04-2020$

DOI: 10.24875/GMM.M21000463 www.gacetamedicademexico.com
access article under the CC BY-NC-ND 


\begin{abstract}
Hemophilia is a hemorrhagic disorder with a sex-linked inherited pattern, characterized by an inability to amplify coagulation due to a deficiency in coagulation factor VIII (hemophilia A or classic) or factor IX (hemophilia B). Sequencing of the genes involved in hemophilia has provided a description and record of the main mutations, as well as a correlation with the various degrees of severity. Hemorrhagic manifestations are related to levels of circulating factor, mainly affecting the musculoskeletal system and specifically the large joints (knees, ankles, and elbows). This document is a review and consensus of the main genetic aspects of hemophilia, from the inheritance pattern to the concept of women carriers, physiopathology and classification of the disorder, the basic and confirmation studies when hemophilia is suspected, the various treatment regimens based on infusion of the deficient coagulation factor as well as innovative factor-free therapies and recommendations for the management of complications associated with treatment (development of inhibitors and/or transfusion-transmitted infections), or secondary to articular hemorrhagic events (hemophilic arthropathy). Finally, relevant reviews of clinical and treatment aspects of hemorrhagic pathology characterized by acquired deficiency of FVIII secondary to neutralized antibodies named acquired hemophilia.
\end{abstract}

KEY WORDS: Hemophilia. Consensus. Review. Acquired Hemophilia A.

\title{
Consenso de hemofilia en México
}

\section{Resumen}

La hemofilia es un trastorno hemorrágico con patrón de herencia ligado al sexo, caracterizado por una incapacidad en la amplificación de la coagulación ocasionada por la deficiencia del factor VIII (hemofilia A o clásica) o del factor IX (hemofilia B). La secuenciación de los genes involucrados en la hemofilia ha permitido la descripción y registro de las principales mutaciones, así como la correlación con los diversos grados de severidad. Las manifestaciones hemorrágicas se relacionan con los niveles de factor deficiente circulante, afectando principalmente al sistema musculoesquelético y en particular a las grandes articulaciones (rodillas, tobillos y codos). El presente documento hace una revisión y consenso de los principales aspectos genéticos de la hemofilia, desde el patrón de herencia y el concepto de mujeres portadoras, la fisiopatología y clasificación de la enfermedad, los estudios básicos y de confirmación ante la sospecha de hemofilia, y de los diversos esquemas de tratamiento basados en la infusión del factor de coagulación deficiente hasta las terapias innovadoras libres de factor, así como de las recomendaciones para el manejo de las complicaciones asociadas al tratamiento (desarrollo de inhibidores y/o infecciones transmitidas por transfusión) o secundarias a los eventos hemorrágicos a nivel articular (artropatía hemofílica). La parte final del documento revisa los aspectos clínicos y de tratamiento relevantes de una patología hemorragica caracterizada por la deficiencia adquirida del FVIII mediada por anticuerpos neutralizantes denominada hemofilia adquirida.

PALABRAS CLAVE: Hemofilia. Consenso. Revisión. Hemofilia A adquirida.

\section{Introduction}

Hemophilia is a hereditary hemorrhagic disorder caused by a quantitative deficiency of coagulation factor VIII, called as hemophilia A (HA) and representing $80 \%$ of cases; or factor IX, known as hemophilia B (HB), corresponding to remaining $20 \%$. Deficiency of these factors causes an inability to generate thrombin and amplify the fluid phase of coagulation, with subsequent hemorrhagic diathesis in persons with hemophilia $(\mathrm{PwH})$. Clinical manifestations of $\mathrm{HA}$ and $\mathrm{HB}$ are similar and depend on the amount of deficient factor in circulation. In severe cases, the main site of bleeding is joints (hemarthrosis), which without adequate integral therapy can develop into a chronic hemophilic arthropathy, which, in turn, represents the main cause of morbidity in this population. The pattern of inheritance is sex-linked recessive ( $X$ chromosome). Thus, males manifest the disease and women are either asymptomatic carriers or present minimal hemorrhagic symptoms. The prevalence and genetic alterations of hemophilia are similar worldwide, with no influence of lineage or ethnic origin.

The milestone of treatment for $\mathrm{PwH}$ is intravenous (IV) infusion of deficient factor. This may be on-demand (during hemorrhagic episodes) or prophylactic (regular 
administration of factor) with the main objective of avoiding spontaneous hemarthrosis, however, with considerable risk of developing inhibitors in severe hemophilia.

The aim of this document is to review and achieve consensus by physicians that treat hemophilia in one of the main health institutions in Mexico, describing basic genetic aspects, pathophysiology and diagnosis of hemophilia, treatment outlines, the main complications, and special problems associated with an increase in survival for $\mathrm{PwH}$. At the end, we analyze acquired hemophilia, where pathophysiology, clinical characteristics, and management differ significantly from congenital hemophilia.

\section{Historical and epidemiological background}

The description of a sex-linked hemorrhagic problem has been recognized since the $2^{\text {nd }}$ century B.C. expressed in the Talmud ${ }^{1}$, relating to care for newborn boys after circumcision when there was a history of bleeding in male siblings. In the $17^{\text {th }}$ century, it was described as "The disease of royalty," since it was transmitted by Queen Victoria to descendants of the thrones of Great Britain, Germany, and Spain. The most recognized case affected Alexei, son of Alexandra (granddaughter of Queen Victoria) and the last Tsar of Russia, Nicholas II'. In 1803, John Conrad Otto, a physician in Philadelphia, published the first article acknowledging a familial bleeding condition that mainly affected men. The term hemophilia, from the Greek heme "blood" and filia "love," was published in 1824 by Hopff. In 1947, Dr. Alfredo Pavlosky, from Buenos Aires Argentina, distinguished two types of hereditary hemophilia ${ }^{3}$.

Global incidence of HA is $1 / 5000$ males born and 1 in 30,000 for $\mathrm{HB}$. At present, there is an estimated of $400,000 \mathrm{PwH}$ in the world. The first report with demographic information, treatment, and complications of PwH worldwide was published in 1999 by the World Federation of Hemophilia (WFH) under the name of Annual Global Survey, that in the last publication with data from 2018, reported a total of 210,454 $\mathrm{PwH}$, with a distribution by severity according to income, which is described in table 1. In Mexico, a total of 5814 cases were reported: 4761 with $\mathrm{HA}$ and 724 with $\mathrm{HB}$, with a predominance of population older than 19 years (Tables 2 and 3 ) and without defining of type of hemophilia in 329 cases $^{4}$.
Table 1. Hemophilia distribution by severity

\begin{tabular}{|l|c|c|c|c|}
\hline Severity & Mild & Moderate & Severe & Unknown \\
\hline Hemophilia A & $19.49 \%$ & $23.26 \%$ & $41.82 \%$ & $15.44 \%$ \\
\hline Hemophilia B & $20.04 \%$ & $28.67 \%$ & $36.42 \%$ & $14.86 \%$ \\
\hline
\end{tabular}

Source: WFH Annual Global Survey, $2018^{4}$.

\section{Pathophysiology}

$\mathrm{HA}$ and $\mathrm{HB}$ are the unique sex-linked hereditary recessive hemorrhagic diseases in $70 \%$ of cases (the rest of cases are consequence of spontaneous de novo mutations). The condition is almost exclusively of male gender due to the $X Y$ genotype ${ }^{1}$, since the genes that encode factors VIII and IX are located on the long arm of chromosome 23 (X chromosome) that determines sex, at positions Xq28 and Xq27, respectively ${ }^{5}$. More than 4000 pathogenic variants in these genes have been described, which cause a quantitative-qualitative decrease in the expression and protein activity of these clotting factors ${ }^{6}$.

For educational purposes, genetic defects in factor VIII can be divided into three groups: (1) genetic rearrangements, such as inversion of intron 22 , which occurs in $45 \%$ of patients with severe hemophilia and is caused by homologous recombination between the 9.5 $\mathrm{kb}$ sequence and 2 extragenic homologous regions, and inversion of intron 1 that occurs in $1-2 \%$ of severe cases; (2) insertions or deletions of genetic sequences; and (3) single DNA base substitutions resulting in missense, nonsense, or frameshift mutations. Figures 1-3 describe the chromosomal abnormalities in HA depending on severity, showing predominance of point mutation, followed by deletions, duplications, and insertions. In HB patients, point mutations occur in most cases, followed by deletions, insertions, and duplications (Figs. 4-6) ${ }^{7}$.

\section{Inheritance pattern}

Figure 7 shows the classic hemophilia inheritance pattern, showing that all daughters of hemophiliac $(X Y)$ patient are obliged carriers when inheriting the affected $X$ chromosome, the male offspring will be healthy on receiving the normal $Y$ chromosome from the father $(X Y)$. In case of women carriers $(X X)$, in each pregnancy, there is $25 \%$ risk of conceiving an affected male child (hemophiliac), $25 \%$ risk of conceiving a carrier daughter, and the remaining 50\% probability of having an unaffected son or daughter. 
Gaceta Médica de México. 2021;157(Supl)

Table 2. Age distribution of patients with hemophilia A

\begin{tabular}{|c|c|c|c|c|c|c|c|}
\hline & Hemophilia A & $0-4$ & $5-13$ & $14-18$ & $19-44$ & $45+$ & $\begin{array}{l}\text { Age not } \\
\text { known }\end{array}$ \\
\hline France & 6,446 & $7 \%$ & $15 \%$ & $10 \%$ & $40 \%$ & $28 \%$ & $0 \%$ \\
\hline Georgia & 270 & $3 \%$ & $21 \%$ & $6 \%$ & $49 \%$ & $21 \%$ & $0 \%$ \\
\hline Ghana & 278 & $10 \%$ & $45 \%$ & $21 \%$ & $14 \%$ & $0 \%$ & $10 \%$ \\
\hline Greece & 815 & $4 \%$ & $8 \%$ & $7 \%$ & $46 \%$ & $34 \%$ & $0 \%$ \\
\hline Guatemala & 250 & $4 \%$ & $17 \%$ & $16 \%$ & $44 \%$ & $9 \%$ & $10 \%$ \\
\hline Guyana & 13 & $0 \%$ & $15 \%$ & $8 \%$ & $62 \%$ & $15 \%$ & $0 \%$ \\
\hline Honduras & 299 & $5 \%$ & $27 \%$ & $14 \%$ & $43 \%$ & $3 \%$ & $7 \%$ \\
\hline Hong Kong (China) & 119 & $3 \%$ & $24 \%$ & $8 \%$ & $55 \%$ & $10 \%$ & $1 \%$ \\
\hline Hungary & 914 & $4 \%$ & $3 \%$ & $5 \%$ & $35 \%$ & $42 \%$ & $11 \%$ \\
\hline India & 17,606 & $2 \%$ & $14 \%$ & $10 \%$ & $38 \%$ & $8 \%$ & $28 \%$ \\
\hline Indonesia & 2,035 & $11 \%$ & $32 \%$ & $16 \%$ & $36 \%$ & $3 \%$ & $1 \%$ \\
\hline Iran & 5,208 & $4 \%$ & $13 \%$ & $8 \%$ & $56 \%$ & $19 \%$ & $0 \%$ \\
\hline Iraq & 1,867 & $23 \%$ & $40 \%$ & $20 \%$ & $15 \%$ & $3 \%$ & $0 \%$ \\
\hline Ireland & 715 & $14 \%$ & $16 \%$ & $8 \%$ & $33 \%$ & $29 \%$ & $0 \%$ \\
\hline Israel & 608 & $10 \%$ & $17 \%$ & $10 \%$ & $39 \%$ & $24 \%$ & $0 \%$ \\
\hline Italy & 4,135 & $3 \%$ & $9 \%$ & $6 \%$ & $40 \%$ & $42 \%$ & $0 \%$ \\
\hline Jamaica & 43 & $5 \%$ & $12 \%$ & $21 \%$ & $33 \%$ & $26 \%$ & $5 \%$ \\
\hline Kenya & 504 & $12 \%$ & $29 \%$ & $27 \%$ & $14 \%$ & $13 \%$ & $4 \%$ \\
\hline Korea, Republic of & 1,721 & $5 \%$ & $11 \%$ & $8 \%$ & $54 \%$ & $23 \%$ & $0 \%$ \\
\hline Kyrgyzstan & 343 & $7 \%$ & $38 \%$ & $14 \%$ & $32 \%$ & $8 \%$ & $0 \%$ \\
\hline Lebanon & 169 & $10 \%$ & $14 \%$ & $14 \%$ & $45 \%$ & $16 \%$ & $1 \%$ \\
\hline Lesotho & 24 & $4 \%$ & $8 \%$ & $63 \%$ & $25 \%$ & $0 \%$ & $0 \%$ \\
\hline Lithuania & 152 & $0 \%$ & $0 \%$ & $0 \%$ & $0 \%$ & $0 \%$ & $100 \%$ \\
\hline Madagascar & 70 & $11 \%$ & $36 \%$ & $11 \%$ & $39 \%$ & $3 \%$ & $0 \%$ \\
\hline Malawi & 35 & $6 \%$ & $31 \%$ & $6 \%$ & $20 \%$ & $0 \%$ & $37 \%$ \\
\hline Malaysia & 900 & $10 \%$ & $19 \%$ & $11 \%$ & $41 \%$ & $10 \%$ & $10 \%$ \\
\hline Maldives & 14 & $14 \%$ & $29 \%$ & $7 \%$ & $29 \%$ & $21 \%$ & $0 \%$ \\
\hline Mali & 128 & $20 \%$ & $48 \%$ & $16 \%$ & $14 \%$ & $0 \%$ & $2 \%$ \\
\hline Mauritania & 61 & $7 \%$ & $48 \%$ & $21 \%$ & $20 \%$ & $5 \%$ & $0 \%$ \\
\hline Mauritius & 74 & $0 \%$ & $9 \%$ & $12 \%$ & $39 \%$ & $28 \%$ & $11 \%$ \\
\hline Mexico & 4,761 & $3 \%$ & $20 \%$ & $11 \%$ & $42 \%$ & $10 \%$ & $14 \%$ \\
\hline Mongolia & 81 & $17 \%$ & $40 \%$ & $9 \%$ & $30 \%$ & $5 \%$ & $0 \%$ \\
\hline Montenegro & 41 & $2 \%$ & $15 \%$ & $12 \%$ & $32 \%$ & $39 \%$ & $0 \%$ \\
\hline Morocco & 183 & $11 \%$ & $36 \%$ & $8 \%$ & $41 \%$ & $4 \%$ & $0 \%$ \\
\hline Myanmar & 464 & $22 \%$ & $36 \%$ & $13 \%$ & $20 \%$ & $3 \%$ & $7 \%$ \\
\hline Nepal & 562 & $13 \%$ & $19 \%$ & $18 \%$ & $36 \%$ & $7 \%$ & $6 \%$ \\
\hline Netherlands & 797 & $6 \%$ & $10 \%$ & $9 \%$ & $32 \%$ & $43 \%$ & $0 \%$ \\
\hline New Zealand & 454 & $4 \%$ & $11 \%$ & $13 \%$ & $36 \%$ & $35 \%$ & $0 \%$ \\
\hline
\end{tabular}

Source: WHF Global Survey, $2018^{4}$.

Overall $50 \%$ of male offspring and $50 \%$ of daughters of carrier mothers will be hemophiliacs or carriers, respectively ${ }^{1}$.
From genetic viewpoint, woman receives double information (paternal and maternal) from the $X$ chromosome. During embryonic period, a random 
Table 3. Age distribution of patients with hemophilia B

\begin{tabular}{|c|c|c|c|c|c|c|c|}
\hline & Hemophilia B & $0-4$ & $5-13$ & $14-18$ & $19-44$ & $45+$ & $\begin{array}{l}\text { Age not } \\
\text { known }\end{array}$ \\
\hline Finland & 33 & $3 \%$ & $27 \%$ & $15 \%$ & $33 \%$ & $21 \%$ & $0 \%$ \\
\hline France & 1498 & $7 \%$ & $17 \%$ & $11 \%$ & $37 \%$ & $28 \%$ & $0 \%$ \\
\hline Georgia & 53 & $6 \%$ & $19 \%$ & $2 \%$ & $49 \%$ & $25 \%$ & $0 \%$ \\
\hline Ghana & 16 & $13 \%$ & $25 \%$ & $25 \%$ & $0 \%$ & $0 \%$ & $38 \%$ \\
\hline Greece & 184 & $4 \%$ & $8 \%$ & $4 \%$ & $39 \%$ & $45 \%$ & $0 \%$ \\
\hline Guatemala & 34 & $3 \%$ & $17 \%$ & $17 \%$ & $29 \%$ & $3 \%$ & $31 \%$ \\
\hline Honduras & 34 & $12 \%$ & $24 \%$ & $18 \%$ & $38 \%$ & $3 \%$ & $6 \%$ \\
\hline Hong Kong (China) & 24 & $0 \%$ & $21 \%$ & $8 \%$ & $38 \%$ & $33 \%$ & $0 \%$ \\
\hline Hungary & 230 & $2 \%$ & $1 \%$ & $4 \%$ & $38 \%$ & $43 \%$ & $12 \%$ \\
\hline India & 2715 & $2 \%$ & $13 \%$ & $12 \%$ & $42 \%$ & $11 \%$ & $21 \%$ \\
\hline Indonesia & 310 & $16 \%$ & $38 \%$ & $19 \%$ & $24 \%$ & $1 \%$ & $3 \%$ \\
\hline Iran & 1109 & $3 \%$ & $12 \%$ & $8 \%$ & $59 \%$ & $18 \%$ & $0 \%$ \\
\hline Iraq & 502 & $23 \%$ & $40 \%$ & $20 \%$ & $13 \%$ & $5 \%$ & $0 \%$ \\
\hline Ireland & 243 & $4 \%$ & $14 \%$ & $11 \%$ & $41 \%$ & $30 \%$ & $0 \%$ \\
\hline Israel & 104 & $14 \%$ & $15 \%$ & $18 \%$ & $37 \%$ & $15 \%$ & $0 \%$ \\
\hline Italy & 886 & $3 \%$ & $10 \%$ & $9 \%$ & $42 \%$ & $37 \%$ & $0 \%$ \\
\hline Jamaica & 4 & $0 \%$ & $0 \%$ & $25 \%$ & $50 \%$ & $25 \%$ & $0 \%$ \\
\hline Kenya & 114 & $18 \%$ & $25 \%$ & $31 \%$ & $21 \%$ & $4 \%$ & $2 \%$ \\
\hline Korea, Republic of & 427 & $4 \%$ & $14 \%$ & $11 \%$ & $49 \%$ & $22 \%$ & $0 \%$ \\
\hline Kyrgyzstan & 40 & $8 \%$ & $15 \%$ & $15 \%$ & $58 \%$ & $5 \%$ & $0 \%$ \\
\hline Lebanon & 47 & $6 \%$ & $11 \%$ & $23 \%$ & $51 \%$ & $9 \%$ & $0 \%$ \\
\hline Lithuania & 24 & $0 \%$ & $0 \%$ & $0 \%$ & $0 \%$ & $0 \%$ & $100 \%$ \\
\hline Madagascar & 57 & $16 \%$ & $46 \%$ & $16 \%$ & $23 \%$ & $0 \%$ & $0 \%$ \\
\hline Malawi & 6 & $0 \%$ & $50 \%$ & $0 \%$ & $17 \%$ & $0 \%$ & $33 \%$ \\
\hline Malaysia & 172 & $8 \%$ & $17 \%$ & $15 \%$ & $41 \%$ & $13 \%$ & $6 \%$ \\
\hline Maldives & 4 & $50 \%$ & $25 \%$ & $25 \%$ & $0 \%$ & $0 \%$ & $0 \%$ \\
\hline Mali & 13 & $62 \%$ & $15 \%$ & $8 \%$ & $15 \%$ & $0 \%$ & $0 \%$ \\
\hline Mauritania & 15 & $7 \%$ & $47 \%$ & $20 \%$ & $20 \%$ & $7 \%$ & $0 \%$ \\
\hline Mauritius & 13 & $8 \%$ & $8 \%$ & $23 \%$ & $46 \%$ & $8 \%$ & $8 \%$ \\
\hline Mexico & 724 & $5 \%$ & $19 \%$ & $11 \%$ & $44 \%$ & $10 \%$ & $12 \%$ \\
\hline Mongolia & 28 & $11 \%$ & $39 \%$ & $18 \%$ & $25 \%$ & $7 \%$ & $0 \%$ \\
\hline Montenegro & 4 & $0 \%$ & $0 \%$ & $25 \%$ & $50 \%$ & $25 \%$ & $0 \%$ \\
\hline Morocco & 34 & $10 \%$ & $29 \%$ & $23 \%$ & $39 \%$ & $0 \%$ & $0 \%$ \\
\hline Myanmar & 76 & $45 \%$ & $33 \%$ & $7 \%$ & $11 \%$ & $4 \%$ & $1 \%$ \\
\hline Nepal & 93 & $8 \%$ & $30 \%$ & $18 \%$ & $27 \%$ & $11 \%$ & $6 \%$ \\
\hline Netherlands & 125 & $3 \%$ & $13 \%$ & $15 \%$ & $31 \%$ & $38 \%$ & $0 \%$ \\
\hline New Zealand & 102 & $4 \%$ & $8 \%$ & $8 \%$ & $33 \%$ & $46 \%$ & $0 \%$ \\
\hline
\end{tabular}

Source: WHF Global Survey, $2018^{4}$.

inactivation of one of two X chromosomes occurs, a biological phenomenon known as lionization, in this way, carriers will have average $50 \%$ of cells that express the normal allele $^{8}$ for synthesis of factor involved, enough to maintain the level of factor around $50 \%$ activity (range between 22 and $116 \mathrm{lU} / \mathrm{dl}$ ) and present as asymptomatic ${ }^{1}$. However, sometimes, lyonization is not random and extreme inactivation of 
Gaceta Médica de México. 2021;157(Supl)

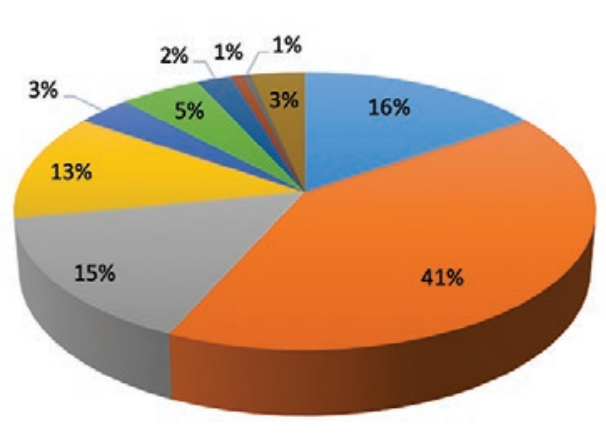

Missense

- Intron 22 inversion

= Frameshift

nonsense

- Splice site

- Large deletion

- Intron 1 inversion

- Small deletion

- Duplication

None

Figure 1. Mutations causing severe hemophilia A. Taken from Miller et al., $2011^{7}$.

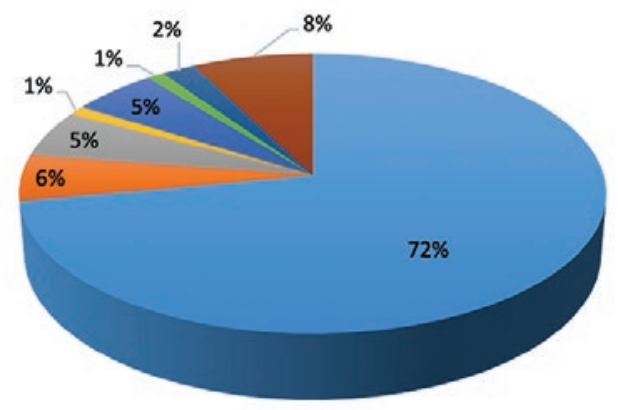

Missense

Intron 22 inversion

arameshift

n Nonsense

- Splice site

- Large deletion

- Duplication

None

Figure 2. Mutations causing moderate hemophilia A. Taken from Miller et al., $2011^{7}$.

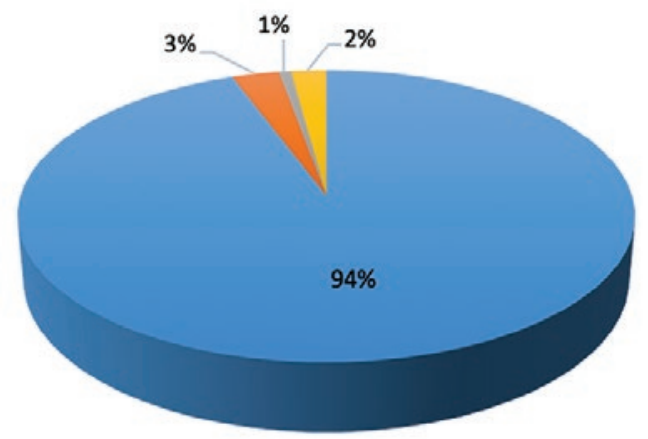

\section{Missense}

- Splice site

- Small deletion

№ne

Figure 3. Mutations causing mild hemophilia A. Taken from Miller et al., $2011^{7}$.

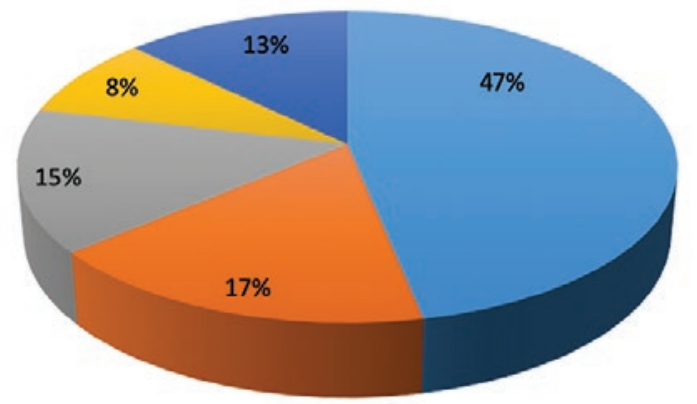

Missense

- Frameshift

톨 Nonsense

Splice site

- Large deletion

Figure 4. Mutations causing severe hemophilia B. Taken from Miller et al., $2011^{7}$. 


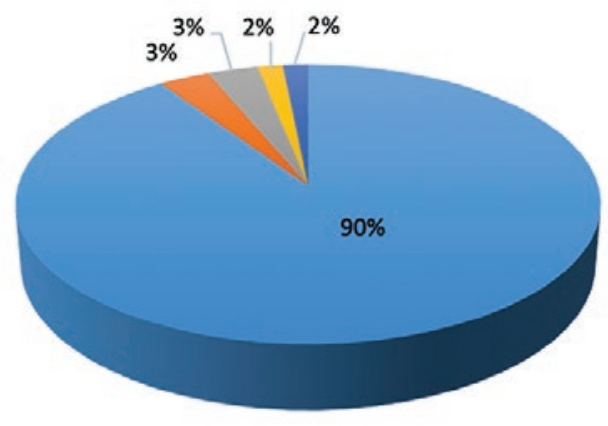

\author{
घissense \\ a Frameshift \\ $\cong$ Nonsense \\ "Small \\ insertion/deletion \\ a' $3^{\prime}$ UTR
}

Figure 5. Mutations causing moderate hemophilia B. Taken from Miller et al., 2011'. $3^{\prime}$ UTR: untranslated region.

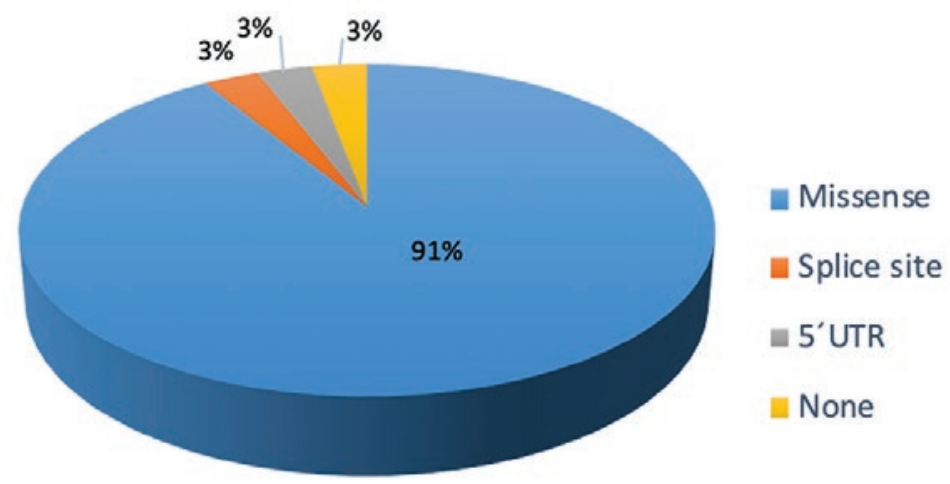

Figure 6. Mutations causing mild hemophilia B. Taken from Miller et al., 20117. 5 'UTR: untranslated region.

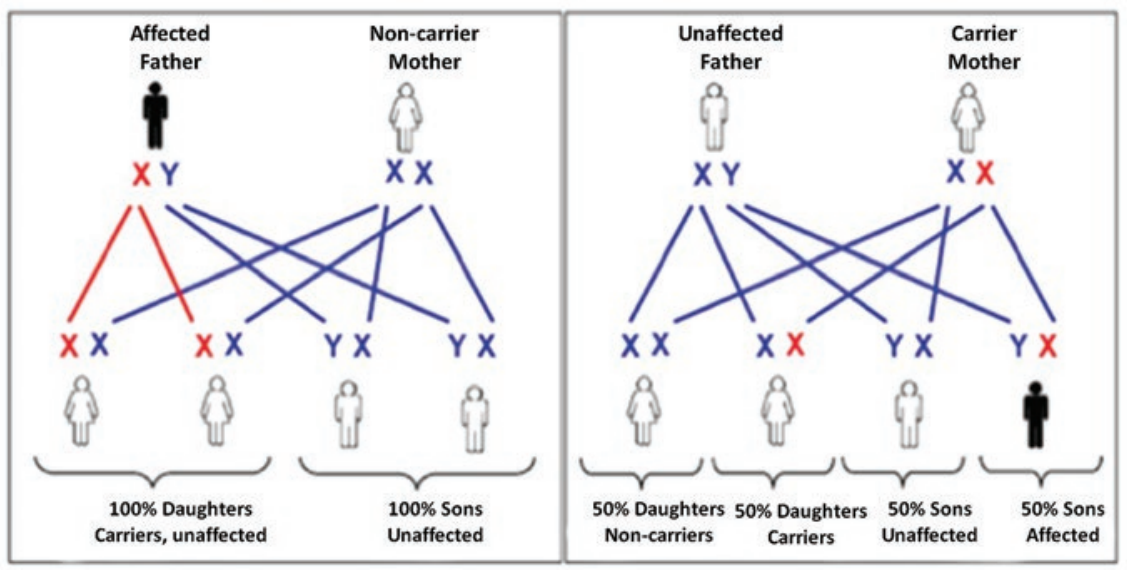

Figure 7. Hemophilia inheritance pattern. In red affected $X$ chromosome and unaffected chromosomes in blue.

the $\mathrm{X}$ chromosome occurs, which generates a dual cell population where most somatic cells have $X$ chromosome with the normal gene inactivated, causing lower expression of the clotting factor and generating the concept of "low-level carriers," with hemorrhagic manifestations similar to a mild or moderate hemophiliac and/or menorrhagia. The same phenomenon of lyonization of $X$ chromosome is responsible for the low levels of factor VIII or IX in women with Turner syndrome or mosaicism of $X$ chromosome. Although hemophilia is a condition that occurs in the hemizygous male and the heterozygous female is a 


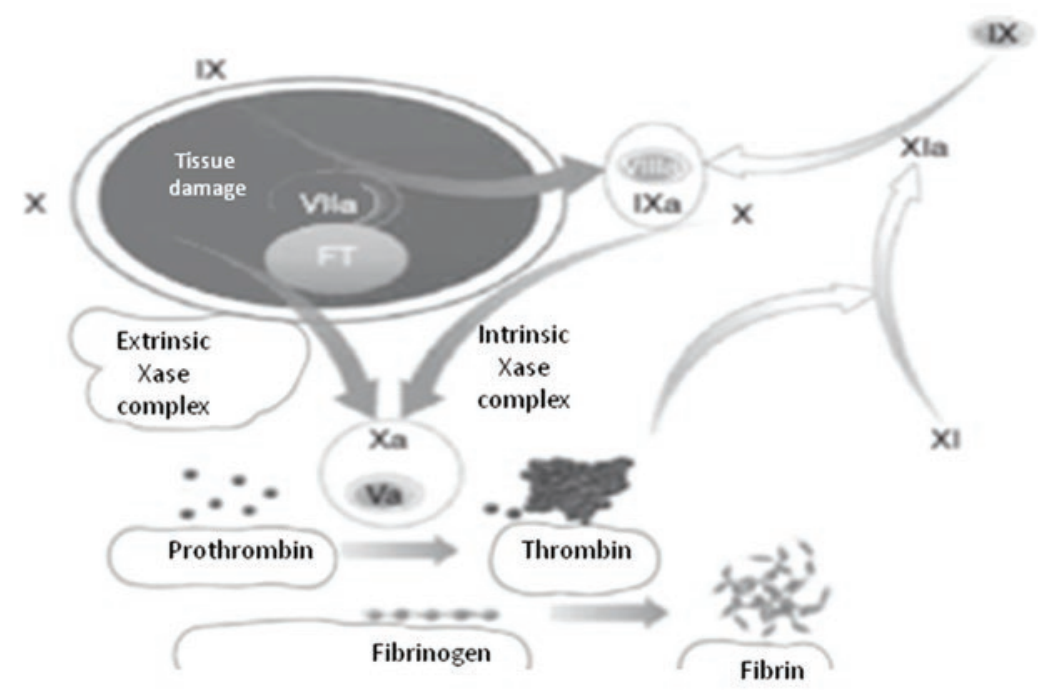

Figure 8. Fluid phase in hemostasis. Adapted from Garcia-Chávez and Majluf-Cruz, 2013'.

generally asymptomatic carrier, ${ }^{\text {(idem) }}$ in theory, a woman can be hemophiliac if the father is hemophiliac and her mother is a carrier.

With the aforementioned genetic background, it is pertinent to mention some relevant aspects of carriers in regard to family history. Obliged carriers are defined as: (1) daughters of a male with hemophilia; (2) mother of a male with hemophilia and family history; (3) mother of a hemophiliac with relative who carries the hemophilia gene; and (4) mother of two or more men with hemophilia. Probable carriers are: (1) all daughters of a carrier; (2) mother of a hemophiliac with no family history of hemophilia; and (3) sisters, mothers, maternal grandmothers, aunts, nieces, and cousins of obliged carriers.

\section{Impaired hemostasis in hemophilia}

Coagulopathy in $\mathrm{PwH}$ is consequence of the inability to magnify, control, and maintain thrombin generation due to FVIII or IX deficiency. Thrombin generation is set up as an event of high biological-physiological value as it is an essential part of the molecular complex responsible for the fluid phase of hemostasis. When there is a tissular lesion, FIXa binds to FVIIIa on a lipid layer rich in tissue factor (TF), producing the "intrinsic Xase" complex, which has the ability to generate $90 \%$ of thrombin in the event of tissue damage, with $10^{6}$ times greater efficiency than FVIII and FIX alone (Fig. 8). This complex is 50 times more effective than the "extrinsic Xase" complex (with a high content of FVlla) for the activation of FX to FXa, with subsequent activation of factor II (prothrombin) into thrombin, which converts soluble fibrinogen (factor I) into fibrin (insoluble) ${ }^{1}$. This simple description of specific segment of hemostasis explains how the absence of factors VIII and IX is clinically manifested with classic bleeding events in $\mathrm{PwH}$.

\section{Diagnosis and classification}

Hemophilia should be suspected in any male who presents with prolonged or excessive bleeding, unrelated to the magnitude of trauma and/or hemorrhage that occurs hours after injury or recurrence. In primary coagulation tests, platelet count, prothrombin time (PT), thrombin time (TT), and fibrinogen will be normal with a prolonged activated partial thromboplastin time (aPTT), which is described later. The hemorrhagic manifestations of $\mathrm{PwH} A$ or $\mathrm{B}$ are clinically indistinguishable, therefore, it is necessary to identify the deficient factor to provide its specific replacement. The definitive diagnosis is based on the quantification of coagulation factors. The World Health Organization (WHO) defined an international unit (IU) as the activity of factor present in $1 \mathrm{ml}$ of plasma, and depending on the nomenclature of each place, it can be equivalently expressed as $1 \mathrm{IU} / \mathrm{dl}, 0.01 \mathrm{IU} / \mathrm{ml}$, or $1 \%$. Severity of hemophilia is classified according to the activity of circulating plasma level of FVIII or FIX without treatment, as severe, moderate, or mild (Table 4) ${ }^{9}$. 
Table 4. Classification of hemophilia and correlation with hemorrhagic manifestations

\begin{tabular}{|c|c|c|}
\hline Severity & $\begin{array}{c}\text { Coagulation factor } \\
\text { level }\end{array}$ & Hemorrhagic episodes \\
\hline Severe & $\begin{array}{c}<1 \mathrm{IU} / \mathrm{dL} \\
(<0.01 \mathrm{IU} \mathrm{mL}) \\
\quad \text { or }<1 \%\end{array}$ & $\begin{array}{l}\text { Spontaneous bleeding in joints } \\
\text { or muscles }\end{array}$ \\
\hline Moderate & $\begin{array}{l}1-5 \mathrm{IU} / \mathrm{dL}(0.01- \\
0.05 \mathrm{IU} \mathrm{mL}) \text { or } \\
1-5 \%\end{array}$ & $\begin{array}{l}\text { Occasional spontaneous } \\
\text { bleeding; prolonged bleeding } \\
\text { after trauma or surgery }\end{array}$ \\
\hline Mild & $\begin{array}{l}5-40 \mathrm{IU} / \mathrm{dL} \\
(0.05-0.40 \mathrm{IU} / \mathrm{mL}) \\
\quad \text { or } 5-40 \%\end{array}$ & $\begin{array}{l}\text { Severe bleeding after trauma } \\
\text { or major surgery. Spontaneous } \\
\text { bleeding is rare }\end{array}$ \\
\hline
\end{tabular}

Adapted from Blanchette and Srivastava, 2015².

\section{Laboratory studies}

Hemostatic studies have a fundamental role in diagnosis and monitoring of $\mathrm{PwH}$. The quality insurance of these tests includes internal and external quality control, as well as control of factors that can influence different stages of test processing, such as pre-analytical phase, where more than $70 \%$ of laboratory errors occur (requisition of studies carried out by the doctor, correct registration of the requested study, preparation, collection, and sampling). This is relevant when considering that coagulation tests are exceptionally susceptible to temperature changes, particularly due to factor VIII thermolability.

The relevant aspects in processing laboratory studies from $\mathrm{PwH}$, and a brief description of findings from screening, confirmatory studies, and detection of inhibitors in hemophilia, are specified below ${ }^{10-12}$.

\section{General aspects}

- Venipuncture: ensure an atraumatic sample with minimal use of the tourniquet, using 19-21G needles (23G gauge in pediatric patients).

- Collection tube with $3.2 \%$ sodium citrate anticoagulant: it must be filled with at least $90 \%$ of what is indicated (9:1 ratio between the sample obtained and the anticoagulant).

- Mix the sample completely with the anticoagulant, gently inverting the tip of the tube 4-6 times and ensuring that clots do not form.

- Sample transportation: at room temperature and centrifugation within the $1^{\text {st }} \mathrm{h}$ of collection. If transporting to a laboratory, preferably freeze the plasma immediately at $-20^{\circ} \mathrm{C}$ or less and transport in dry ice.

- Fasting: not mandatory, although an excess of lipids can affect analytical analyzers.

\section{SCREENING STUDIES FOR SUSPECTED HEMOPHILIA}

- Complete blood count: within the reference parameters, if there is no other justifiable alteration.

- Normal PT and prolonged aPTT.

- Plasma correction: in congenital hemophilia, the aPTT will be corrected by mixing the patient's plasma in a 1:1 ratio with normal plasma. If the mixture does not correct the prolonged aPTT, it may indicate the presence of an inhibitor or presence of an anticoagulant in plasma.

\section{Confirmatory Studies for factor VIII AND IX DOSAGE}

Factor VIII determination can be performed by chromogenic or clotting assay. Factor IX dosage is determined by a one-stage clotting test. Performing a comprehensive dosage determination of all factors that can prolong aPTT (VIII, IX, XI, and XII) during the initial evaluation is recommended. When there is a family history of hemophilia, FVIII or IX activity in umbilical cord blood of male newborns can be determined.

Consensus Recommendation: in patients without a hereditary history of hemophilia, with a clinical hemorrhagic profile and prolonged aPTT, perform plasma corrections and confirm the activity of the deficient coagulation factor by means of chromogenic or coagulation assay for FVIII and coagulation assay for FIX. In cases with a family history of hemophilia, carry out the deliberate search to determine the specific coagulation factor in umbilical cord blood or peripheral blood of the newborn.

\section{DETECTION OF ANTI-FACTOR VIII AND ANTI-FACTOR IX ANTIBODIES (INHIBITORS)}

Anti-FVIII or FIX antibodies are IgG-type alloantibodies with neutralizing (inhibiting) or non-neutralizing activity of clotting factor activity and represent a serious complication of clotting factor concentrate (CFC) replacement therapy, therefore, they are more frequent in severe $\mathrm{PwH}$. They should be suspected in patients with an inadequate clinical response to the administration of deficient factor, particularly if they 
had previously responded and/or there is a change in the hemorrhagic phenotype ${ }^{12}$.

Confirmation of the inhibitor and titer quantification is carried out using the Bethesda assay or its Bethesda-Nijmegen modification, the latter having greater sensitivity and specificity. This consists of mixing equal volumes of the test plasma with normal plasma, incubation at $37^{\circ} \mathrm{C}$ for $2 \mathrm{~h}$, and measuring the residual activity of factor in the mixture, using a factor VIII or IX free plasma as a control. By definition, a Bethesda unit (BU) is the inhibitor titer that neutralizes $50 \%$ of factor activity in $1 \mathrm{ml}$ of plasma.

If after incubation, the residual factor equals 100\% of the level in the control sample, then the inhibitor level is zero. If residual factor VIII equals $50 \%$ or $25 \%$ of control, the inhibitor level is 1 or $2 \mathrm{BU}$, respectively (Figure 9). In case of result lower than $25 \%$, the patient's plasma is subjected to various degrees of dilution until the result can be read in the graph and the result is multiplied by the dilution factor to be expressed in BU. For example, if a plasma mixture is diluted 1:5 before incubation, and the residual factor is $50 \%$, or one unit, $1 \times 5=5 \mathrm{BU}^{13,14}$.

\section{Consensus Recommendation}

Search for inhibitors using the Bethesda-Nijmegen technique in patients without previous coagulation factor exposure (PUP, Previously Untreated Patients) at $20,50,100$, and 150 exposure day $\left(E D^{1}\right)$.

In patients previously treated with coagulation factors (hereinafter PTP), perform an inhibitor search in case of changes in the hemorrhagic phenotype and before scheduled surgeries.

\section{Differential diagnosis}

Once the decrease in factor VIII has been documented, the possible causes are congenital HA, acquired HA (AHA), or von Willebrand disease (VWD) type $2 \mathrm{~N}$. Thus, differential diagnosis must be carried out to differentiate between these pathologies (Table 5) taking into consideration the clinical characteristics of bleeding pattern, age of presentation, hereditary history, and a VWD panel (at least von Willebrand antigen and multimers, and ristocetin cofactor).

\section{Genetic diagnosis}

Genetic information for PwH represents a useful tool for predicting the risk of inhibitor development and

1 ED is defined as the infusion of FVIII or IX administered in 24 hours.

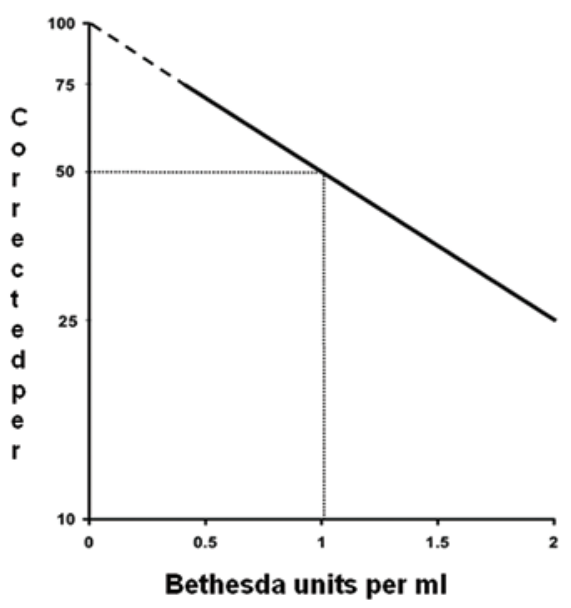

Figure 9. Correlation between residual factor VIII and Bethesda units. Taken from Diagnostico y Tratamiento de inhibidores de los factores VIII y IX, 2004'3.

Table 5. Differential diagnosis of FVIII deficiency

\begin{tabular}{l|l|l|l|l|}
\hline $\begin{array}{l}\text { Possible } \\
\text { diagnosis }\end{array}$ & PT & aPTT & BT & Platelets \\
\hline $\begin{array}{l}\text { Hemophilia A } \\
\text { or B }\end{array}$ & Normal & Prolonged & Normal & Normal \\
VWD & Normal & $\begin{array}{l}\text { Normal or } \\
\text { prolonged }\end{array}$ & $\begin{array}{l}\text { Normal or } \\
\text { prolonged }\end{array}$ & $\begin{array}{l}\text { Normal or } \\
\text { reduced }\end{array}$ \\
$\begin{array}{l}\text { Acquired } \\
\text { hemophilia }\end{array}$ & Normal & Prolonged & Normal & Normal \\
\hline
\end{tabular}

Table adapted from Srivastava et al., 2020². VWD: von Willebrand Disease, BT: bleeding time

facilitates prenatal counseling in carriers. For $\mathrm{PwH} \mathrm{A}$, the initial genetic screening searching for intron inversion 22 and 1. If these alterations are not detected, the complete sequencing of the F8 gene is performed. For HB, the eight exons of the F9 gene are sequenced to detect mutations or deletions ${ }^{10}$.

Genetic study for carriers can be complex. In this cases, FVIII and FIX genes sequencing is the study of choice that allows detecting the genetic rearrangement with a reliability of $99 \%{ }^{15}$. About $80 \%$ of mothers of sporadic cases may be carriers of a mutation, in the remaining $20 \%$ of cases, a mutation is not detected and may be secondary to mosaicism.

Prenatal diagnosis is an integral part of care for hemophilia carriers and is relevant for completion of pregnancy. Studies include non-invasive techniques for product, such as gender screening by analyzing fetal DNA in maternal blood (feasible in the first trimester of pregnancy) or by ultrasound from 15 weeks 
of pregnancy, which are not conclusive; or by invasive methods as chorionic villi sampling between 10 and 12 weeks gestation; amniocentesis, which can be performed between 15 and 18 weeks gestation. If karyotype $46 \mathrm{XY}$ is present, genetic studies of extracted DNA can be performed. Cordocentesis (umbilical cord sample), which is used between 18 and 21 weeks of pregnancy is useful to FVIII and/or FIX measure ${ }^{16}$.

Recommendation: centers that have diagnostic resources should carry out genetic profile of $\mathrm{PwH}$, beginning with screening for inversion 1 and 22 in case of $H A$. If negative, carry out complete sequencing of the F8 gene. For $H B$, perform the sequencing of the F9 gene in the patient, as well as in carriers and/or send samples for research protocols.

\section{Clinical manifestations}

Clinical phenotype of $\mathrm{PwH}$ is tendency to hemorrhage, which is correlated with the level of activity of circulating coagulation factor (Table 4). In severe $\mathrm{PwH}, 90 \%$ have abnormal bleeding in the $1^{\text {st }}$ year of life. The principal site of bleeding occurs in musculoskeletal system, as described in table 6 . Hemarthrosis is the main hemorrhagic manifestation in $\mathrm{PwH}$, it is clinically described as a "tingling" or "aura" sensation in the joint that precedes the classic signs of heat, edema, pain, and limited range of motion. The presence of three or more spontaneous bleeds into a joint within a 6-month period is defined as "target joint" and presents progressive and irreversible changes such as deformation, limited movement, and chronic pain that may warrant surgical management and rehabilitation therapy.

All bleeding in PwH is severe, however, there are anatomical areas that are life threatening and deserve immediate treatment (Table 7). Intracranial hemorrhage $(\mathrm{ICH})$, whether spontaneous or after mild trau$\mathrm{ma}$, is the leading cause of death, therefore, all $\mathrm{PwH}$ with clinical suspicion of $\mathrm{ICH}$ should be treated with the immediate application of CFC before any diagnostic procedure. Bleeding in the neck or throat and at gastrointestinal level also represents an emergency in $\mathrm{PwH}$, due to risk of retropharyngeal hematomas that may occlude the airway or trigger hypovolemic shock, respectively. At this moment, it is pertinent to mention the iliopsoas hematoma, characterized in its severe forms by massive retroperitoneal hemorrhage and manifesting with pain in the groin or iliac fossa and an antalgic position of ipsilateral hip flexion that is
Table 6. Approximate frequency of bleeding at different sites

\begin{tabular}{l|c|}
\hline Bleeding site & Approximate frequency, \% \\
\hline $\begin{array}{l}\text { Hemarthrosis } \\
\text { More frequent in joints with } \\
\text { mobility: ankles, knees, and }\end{array}$ & $70-80$ \\
elbows. Less frequent in multiaxial & \\
joints: shoulders, wrists, and hips. & \\
Muscles & \\
Other major bleeding & $10-20$ \\
CNS & $5-10$ \\
\hline
\end{tabular}

Taken from Srivastava, et al., 202012.

Table 7. Hemorrhagic sites in hemophilia

\begin{tabular}{l|l}
\hline Serious & Life threatening \\
\hline $\begin{array}{l}\text { Joints (hemarthrosis) } \\
\begin{array}{l}\text { Muscles, especially in deep compartments } \\
\text { (iliopsoas, calf, and forearm) }\end{array}\end{array}$ & Intracranial \\
$\begin{array}{l}\text { Mucosae (mouth, gums, nose, and } \\
\text { genitourinary tract) }\end{array}$ & Gastrointestinal \\
\hline $\begin{array}{l}\text { Taken from Srivastava, et al. 202012 } \\
\text { Mon }\end{array}$ & \\
\hline
\end{tabular}

Taken from Srivastava, et al., $2020^{12}$.

sometimes confused with an appendicular profile, delaying specific management, and favoring potential complications $^{12}$.

\section{Treatment}

\section{Multidisciplinary management}

Proper attention to diverse needs of $\mathrm{PwH}$ and their family is given through the intervention of a multidisciplinary team consisting of nurses, psychologist, nutrition, orthopedics, rehabilitation, stomatology, occupational therapy, social workers, and genetics, coordinated by the hematologist and in adherence to national treatment guidelines. All team members must have experience and ability to treat bleeding disorders and be available to care for patients in a timely manner. There must be the infrastructure of a hemophilia treatment center for emergency care all times, with access to specific laboratory studies (determination of clotting factors and inhibitors), as well as necessary drugs and CFC.

The multidisciplinary team will inform to patient and family members about the early symptoms of a hemorrhage with goal of getting timely treatment, and will train them on storage, preparation, and technique for applying coagulation factors, as well as care for 
venous accesses in $\mathrm{PwH}$, since they constitute vital access lines, thereby establishing an effective link between patients, family, and members of comprehensive care team that will promote adherence to treatment, based on the following recommendations ${ }^{12,17}$ :

- Use butterfly needles caliber 23 or $25 \mathrm{G}$.

- Do not perform venous dissection, except in cases of emergency.

- After venipuncture, apply pressure for 3-5 min. Avoid use of permanent devices for venous access as much as possible, although they may be necessary for specific cases.

\section{Pharmacotherapy}

The first-line pharmacological treatment in hemophilia is infusion of deficient CFC, either recombinant or plasma derived. Therapeutic application options can be on-demand or prophylactic, as outlined below.

\section{ON-DEMAND TREATMENT}

This is the application of CFC when there is clinical evidence of acute hemorrhage, calculating the dose to increase the activity of factor according to severity of hemorrhage. On-demand treatment has been shown to decrease mortality and progression of arthropathy, but not prevent it ${ }^{18,19}$. For life-threatening hemorrhage, the starting dose of CFC should be given immediately, even before completing the initial diagnostic evaluation, to obtain $80 \%-100 \%$ activity, whereas in mild-to-moderate bleeding, the goal is to maintain a factor activity between $35 \%$ and $50 \%$. Maintenance doses for HA are generally administered every $12 \mathrm{~h}$ and every $24 \mathrm{~h}$ for HB. Doses and duration of CFC treatment will depend on site, severity of bleeding, and response to treatment (Table 8) $)^{12,17}$.

Any acute bleeding in $\mathrm{PwH}$ should be treated as soon as possible, preferably within the first $2 \mathrm{~h}$ of having occurred. When in doubt about the symptoms in a patient with hemophilia, CFC should be applied. According to the operational guidelines for the care of the patient with hemophilia in the emergency department of $I M S S^{20}$, all PwH admitted to the emergency department for bleeding event should be classified as bright red triage.

The IV bolus application of CFC is calculated considering the ideal weight of $\mathrm{PwH}$ as follows:

- Factor VIII
- Patient weight in $\mathrm{Kg} \times(\%$ factor desired $) \times(0.5)$

- Factor IX

- Patient weight in $\mathrm{Kg} \times(\%$ factor desired $)$

Half-life of the available factor, the purity, the presence of other components such as von Willebrand factor, or recombinant factor should be considered. Recombinant FIX ( $\mathrm{FFIX}$ ) has a lower response than plasma-derived products so that each unit of FIX infused per kilogram will raise FIX activity by approximately $0.8 \mathrm{IU} / \mathrm{dl}$ in adults and $0.7 \mathrm{IU} / \mathrm{dl}$ in children younger than 15 years. The reason for the lower rFIX response has not been fully determined.

When type of hemophilia is unknown, the administration of activated prothrombin complex concentrate (aPCC) is recommended at a dose of 50-100 $\mathrm{U}$ per kg of weight, without exceeding daily dose of $200 \mathrm{U} / \mathrm{kg} /$ day.

Response to treatment in cases of acute hemarthrosis is determined according to criteria in table 9 , which allows to evaluate response in a standardized manner, facilitate comparison of results from different studies, and make therapeutic decisions ${ }^{12}$.

\section{Coaduuvant treatments}

There are other therapeutic options that can help for the management of bleeding in $\mathrm{PwH}$, which are highly relevant, especially in places where CFCs are limited or unavailable:

\section{Desmopressin (DDAVP)}

DDAVP is a synthetic analogue of vasopressin that increases serum levels of factor VIII and von Willebrand factor, the expression of TF, and stimulates platelet adhesion. Therefore, its use is reserved for patients with mild HA.

Dose:

- $0.3 \mu \mathrm{g} / \mathrm{Kg}$ of weight every $12 \mathrm{~h}$, IV or subcutaneous use.

- $150 \mu \mathrm{g}$ of nasal spray in each nostril for adults > $40 \mathrm{~kg}$ in weight.

Due to liquid retention, DDAVP must be used carefully in young children, it is contraindicated for children under 2 years of age due to risk of seizures secondary to cerebral edema from water retention.

\section{Antifibrinolytics}

Antifibrinolytic agents, such as tranexamic acid and epsilon aminocaproic acid, inhibit fibrinolysis, decreasing 
Table 8. Initial and maintenance doses of CFC with respect to the bleeding site

\begin{tabular}{|c|c|c|c|c|c|}
\hline Type de hemorrhage & $\begin{array}{c}\% \text { activity of the } \\
\text { factor desired } \\
\text { HA }\end{array}$ & $\begin{array}{l}\text { Dose of factor } \\
\text { VIII U/kg }\end{array}$ & $\begin{array}{l}\text { Dose of factor } \\
\text { IX U/kg }\end{array}$ & $\begin{array}{l}\% \text { activity of the } \\
\text { factor desired } \\
\text { HB }\end{array}$ & Duration (days) \\
\hline $\begin{array}{l}\text { CNS/head } \\
\text { Initial } \\
\text { Maintenance }\end{array}$ & $\begin{array}{l}80-100 \\
50\end{array}$ & $\begin{array}{c}40-50 \\
25\end{array}$ & $\begin{array}{c}60-80 \\
30\end{array}$ & $\begin{array}{c}60-80 \\
30\end{array}$ & $\begin{array}{c}1-7 \\
8-21\end{array}$ \\
\hline $\begin{array}{l}\text { Airways (neck) } \\
\text { Initial } \\
\text { Maintenance }\end{array}$ & $\begin{array}{l}80-100 \\
50\end{array}$ & $\begin{array}{c}40-50 \\
25\end{array}$ & $\begin{array}{c}60-80 \\
30\end{array}$ & $\begin{array}{c}60-80 \\
30\end{array}$ & $\begin{array}{c}1-7 \\
8-14\end{array}$ \\
\hline $\begin{array}{l}\text { Iliopsoas and deep muscle with NV le } \\
\text { Initial } \\
\text { Maintenance }\end{array}$ & $\begin{array}{c}80-100 \\
30-60\end{array}$ & $\begin{array}{l}40-50 \\
15-30\end{array}$ & $\begin{array}{l}60-80 \\
30-50\end{array}$ & $\begin{array}{l}60-80 \\
30-50\end{array}$ & $\begin{array}{c}1-2 \\
3-5 \\
\text { Secondary } \\
\text { prophylaxis during } \\
\text { physiotherapy }\end{array}$ \\
\hline $\begin{array}{l}\text { Major surgery } \\
\text { Pre-operative } \\
\text { Post-operative }\end{array}$ & $\begin{array}{l}80-100 \\
60-80 \\
40-60 \\
30-50\end{array}$ & $\begin{array}{l}40-50 \\
30-40 \\
20-30 \\
15-25\end{array}$ & $\begin{array}{l}60-80 \\
40-60 \\
30-50 \\
20-40\end{array}$ & $\begin{array}{l}60-80 \\
40-60 \\
30-50 \\
20-40\end{array}$ & $\begin{array}{c}1-3 \\
4-6 \\
7-14\end{array}$ \\
\hline $\begin{array}{l}\text { Minor surgery } \\
\text { Pre-operative } \\
\text { Post-operative }\end{array}$ & $\begin{array}{l}50-80 \\
30-80\end{array}$ & $\begin{array}{l}25-40 \\
15-40\end{array}$ & $\begin{array}{l}50-80 \\
30-80\end{array}$ & $\begin{array}{l}50-80 \\
40-60\end{array}$ & $\begin{array}{l}1-5 \text {, depends on the } \\
\text { type of procedure }\end{array}$ \\
\hline Renal & 50 & 25 & 40 & 40 & $3-5$ \\
\hline Deep laceration & 50 & 25 & 40 & 40 & $5-7$ \\
\hline $\begin{array}{l}\text { Gastrointestinal } \\
\text { Initial } \\
\text { Maintenance }\end{array}$ & $\begin{array}{c}80-100 \\
50\end{array}$ & $\begin{array}{c}40-50 \\
25\end{array}$ & $\begin{array}{c}60-80 \\
30\end{array}$ & $\begin{array}{c}60-80 \\
30\end{array}$ & $\begin{array}{c}1-6 \\
7-14\end{array}$ \\
\hline Hemarthrosis & $40-60$ & $20-30$ & $40-60$ & $40-60$ & $1-2$ or until response \\
\hline Muscular, superficial, unaffected NV & $40-60$ & $20-30$ & $40-60$ & $40-60$ & $\begin{array}{l}2 \text { a } 3 \text {, or until } \\
\text { response }\end{array}$ \\
\hline
\end{tabular}

NV: neurovascular.

Adapted from Guía de Práctica Clínica IMSS, 201717 and Srivastava, et al., 2020².

\section{Table 9. Criteria for evaluating response to treatment in acute hemarthrosis}

$\begin{array}{ll}\text { Level of response } & \begin{array}{l}\text { Response to treatment } \\ \text { Excellent }\end{array} \\ \text { Good } & \begin{array}{l}\text { Complete disappearance of pain in } 8 \mathrm{~h} \text { and/or disappearance of signs of bleeding after the first factor infusion and } \\ \text { without subsequent dose requirements for relief of symptoms and signs in the same joint, in } 72 \mathrm{~h}\end{array} \\ \text { Moderate } & \begin{array}{l}\text { Significant improvement of pain or signs of bleeding at } 8 \mathrm{~h} \text { after initial factor administration, but requiring } \\ \text { subsequent doses in the following } 72 \mathrm{~h} \text { for complete resolution }\end{array} \\ \text { Poor } & \text { the following } 72 \mathrm{~h} \text {, but without complete resolution }\end{array}$

Taken from Srivastava, et al., $2020^{12}$.

the activation of plasminogen to plasmin increasing clot stability. These drugs are useful in the management of bleeding in mucosa (oral, nasal, and menstrual cavities).
Its use is contraindicated in hematuria, since it can prevent the dissolution of clots in the ureters, which would lead to severe obstructive uropathy. 
Table 10. Pharmacological management for acute or chronic pain in hemophilia

\begin{tabular}{|c|c|c|c|}
\hline \multicolumn{2}{|l|}{ Children } & \multicolumn{2}{|l|}{ Adults } \\
\hline Acute pain & Chronic pain & Acute pain & Chronic pain \\
\hline $\begin{array}{l}\text { 1. Paracetamol } \\
\text { 2. Paracetamol }+ \text { weak opioid } \\
\text { 3. Opioid under hospitalization }\end{array}$ & $\begin{array}{l}\text { 1. Paracetamol } \pm \text { adjuvant therapy } \\
\text { 2. Paracetamol }+ \text { weak opioid } \\
\text { 3. Refer to pain therapy }\end{array}$ & $\begin{array}{l}\text { a) Without comorbidities: } \\
\text { 1. Paracetamol } \pm \text { adjuvant } \\
\text { therapy } \\
\text { 2. Paracetamol + weak opioid } \\
\text { or metamizole or COX-2 } \\
\text { 3. Tramadol or strong opioid } \\
\text { b) With liver damage: } \\
\text { 1. Close monitoring with the } \\
\text { use of paracetamol and } \\
\text { metamizole; } \\
\text { 2. Reduce maximum dose } \\
\text { according to prescription } \\
\text { guidelines. }\end{array}$ & $\begin{array}{l}\text { a) Without comorbidities: } \\
\text { 1. Paracetamol } \\
\text { 2. COX-2 or non-selective NSAID } \pm \\
\text { PPI or paracetamol + weak opioid } \\
\text { 3. Tramadol or strong opioid } \pm \\
\text { non-opioid } \\
\text { b) Mild-to-moderate liver damage: } \\
\text { 1. Close monitoring with the use of } \\
\text { paracetamol and metamizole; } \\
\text { 2. Reduce maximum dose according } \\
\text { to prescription guidelines; } \\
\text { 3. COX-2 or non-selective NSAID } \\
\pm \text { PPI only in patients with } \\
\text { mild chronic liver disease and } \\
\text { monitoring renal function. } \\
\text { c) With cardiovascular disease or } \\
\text { risk: } \\
\text { 1. NSAIDs with caution; } \\
\text { 2. Preferably use a COX-2 inhibitor } \\
\text { (naproxen or ibuprofen), consider } \\
\text { using jointly with PPI; } \\
\text { 3. Avoid prolonged use of NSAIDs. }\end{array}$ \\
\hline
\end{tabular}

PPI: proton-pump inhibitor, NSAID: nonsteroidal anti-inflammatory drug Adapted from Auerswald et al., $2016^{21}$

\section{Tranexamic acid}

In Mexico, there is a $650 \mathrm{mg}$ tablet (Lysteda), which is administered orally 3-4 times/day. The injectable presentation of $500 \mathrm{mg} / 5 \mathrm{ml}$ (Amchafibrin) is recommended 2-3 times/day intravenously. For pediatric patients, the recommended dose is $10 \mathrm{mg} / \mathrm{kg}$ weight/day, intravenously 3-4 times/day, or $15 \mathrm{mg} / \mathrm{kg}$ day in 3 oral doses, with a maximum of $4 \mathrm{~g} /$ day.

\section{Epsilon aminocaproic acid}

Presentation in Mexico is as an injectable solution in a bottle with a $5 \mathrm{~g}$ ampule in $20 \mathrm{ml}$ (Amicar). The recommended dose for IV infusion for adults is $4-5 \mathrm{~g}$ in $250 \mathrm{ml}$ of diluent administered during the $1^{\text {st }} \mathrm{h}$, followed by a continuous infusion of $1 \mathrm{~g} / \mathrm{h}$ in $50 \mathrm{ml}$ of diluent until the hemorrhage has been controlled. The pediatric dose is $100 \mathrm{mg} / \mathrm{kg} \mathrm{3-4}$ times a day.

\section{Fresh frozen plasma (FFP) and cryoprecipitates}

Blood products containing clotting factors do not undergo viral or prion inactivation procedures, so their use is restricted exclusively for emergencies, when they are the only option available. The use of cryoprecipitates containing between 3 and $5 \mathrm{IU} / \mathrm{ml}$ of FVIII, or in general $100 \mathrm{IU}$ of FVIII per unit, is preferred over FFP for the treatment of HA. FFP and plasma devoid of cryoprecipitate contain FIX at a concentration of $1 \mathrm{IU} / \mathrm{ml}$, so they can be used to treat HB.

In addition to the coadjuvant therapies for the control of bleeding mentioned above, there are support measures for managing pain caused mainly by the musculoskeletal condition in $\mathrm{PwH}$ and/or during surgical interventions.

\section{ANALGESIA}

PwH may present acute pain associated with bleeding events, such as hemarthrosis, and/or chronic pain due to arthropathy. Recommendations for pain management in adults or pediatric patients are found in table $10^{21}$ :

\section{SURGICAL PREPARATION OF THE PERSON WITH HEMOPHILIA}

The increase in life expectancy of $\mathrm{PwH}$ has conditioned the presence of chronic complications typical of the disease, as well as those related to age, which 
Table 11. Classification of risk of bleeding in surgery for people with hemophilia

\begin{tabular}{|l|l|l|l}
\hline & General surgery & Orthopedic & Other \\
\hline Major & $\begin{array}{l}\text { Procedures: } \\
\text { "ectomy," "otomy," pseudotumor }\end{array}$ & $\begin{array}{l}\text { Arthrodesis and osteotomy, } \\
\text { Joint replacement or arthroplasty, } \\
\text { Synovectomy, } \\
\text { Fracture reduction, } \\
\text { Osteosynthesis, } \\
\text { Arthroscopy, } \\
\text { Amputation. }\end{array}$ & $\begin{array}{l}\text { Dental, with } 3 \text { teeth or more, or extraction } \\
\text { of }\end{array}$ \\
\hline & & Arthroscopic, chemical, or radiation & Dental with $<3$ teeth. \\
\hline Minor & $\begin{array}{l}\text { Placement or removal of central } \\
\text { venous access. }\end{array}$ & Cataract surgery.
\end{tabular}

Taken from Solimeno, $2018^{23}$.

Table 12. Hemostatic response in surgical procedures

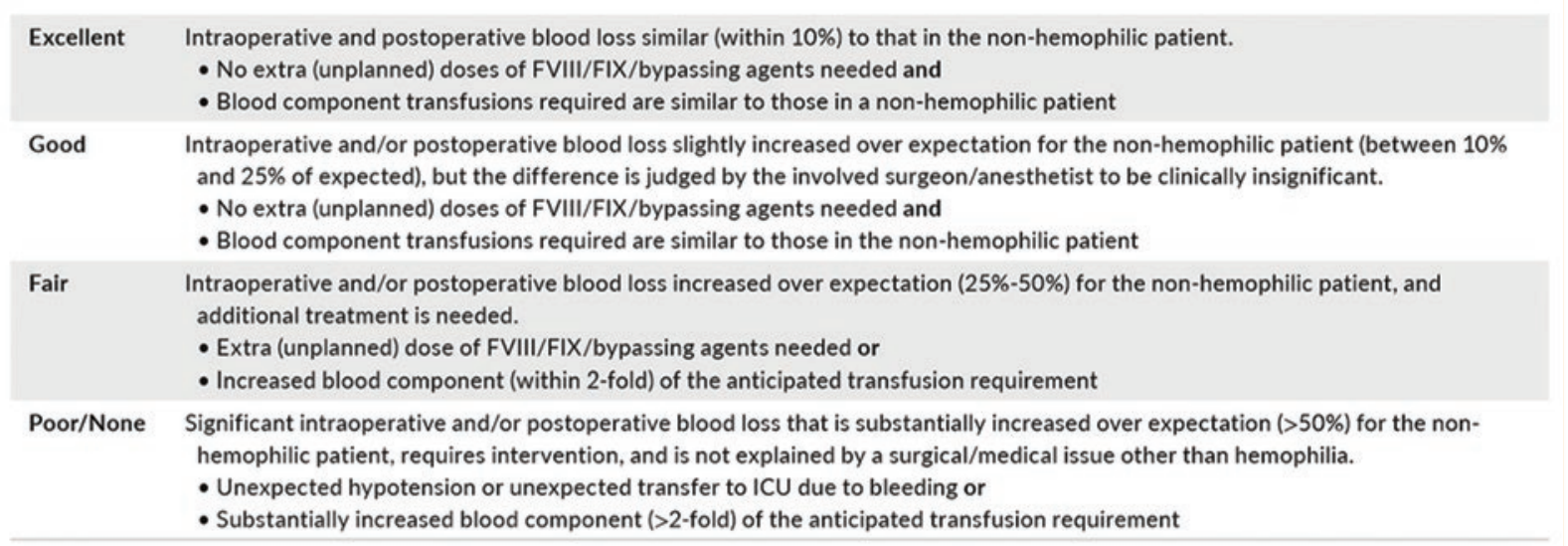

Notes: Apart from estimates of blood loss during surgery, data on pre- and postoperative hemoglobin levels and the number of packed red blood cell units transfused may also be used, if relevant, to estimate surgical blood loss. Surgical hemostasis should be assessed by an involved surgeon and/ or anesthetist, and records should be completed within $72 \mathrm{~h}$ post-surgery. Surgical procedures may be classified as major or minor. A major surgical procedure is defined as one that requires hemostatic support for periods exceeding 5 consecutive days.

Abbreviations: FIX, factor IX; FVIII, factor VIII; ICU, intensive care unit.

Taken from Srivastava et al., $2020^{12}$

is why preparation for scheduled surgical events is necessary. Classifying the risk of bleeding into greater or lesser is recommended, according to the type of surgery (Table 11) and coordinated planning of the multidisciplinary care team before, during, and after surgical event ${ }^{22,23}$.

The efficacy of hemostasis during a surgical event can be evaluated using the criteria published by the WFH (Table 12).

\section{Prophylactic treatment}

Prophylactic treatment consists of regular administration of CFC in the absence of bleeding. It is the ideal treatment for patients with a severe hemorrhagic phenotype, its main objective is to avoid or minimize spontaneous hemarthrosis events and the sequelae of hemophilic arthropathy ${ }^{24-28}$. Table 13 describes types of prophylactic treatment, which consider factors such as age of onset, current age, venous access, hemorrhagic phenotype, joint status, physical activity, availability, access, and presentation of factor, to make the decision, together with patient and family, about the most appropriate treatment option ${ }^{12,29-34}$.

\section{INITIATING PROPHYLAXIS REGIMEN}

Evidence establishes that early prophylaxis $(<36$ months of age) is effective in terms of quality of life and reducing the risk of joint damage. The ESPRIT study (Evaluation Study on Prophylaxis: a Randomized Italian Trial) used rFVIII at a dose of $25 \mathrm{IU} / \mathrm{Kg}$ 
Table 13. Hemophilia prophylaxis schemes

\begin{tabular}{|c|c|c|c|}
\hline Type of prophylaxis & Definition & Clinical objective & Evidence \\
\hline \multicolumn{4}{|c|}{ Continuous prophylaxis } \\
\hline Primary & $\begin{array}{l}\text { Continuous }^{\&} \text { application of CFC } \\
\text { after first hemarthrosis event in } \\
\text { large joints }{ }^{\star} \text {, without arthropathy } \\
\text { detected by clinical or imaging } \\
\text { findings and before } 3 \text { years old. }\end{array}$ & $\begin{array}{l}\text { Prevent or minimize the incidence } \\
\text { of bleeding and hemophilic } \\
\text { arthropathy, as well as its impact } \\
\text { on the psychosocial development } \\
\text { of children and quality of life. Allow } \\
\text { physical activity. }\end{array}$ & $\begin{array}{l}\text { Controlled clinical trials (JOS }{ }^{24} \text {, } \\
\text { ESPRIT }^{30} \text { ); } \\
\text { Prospective study (Canada); } \\
\text { Cohorts: retrospective (Sweden, Holland, } \\
\text { Germany, USA, United Kingdom) and } \\
\text { comparative (France vs. Holland and } \\
\text { Sweden; Norway vs. Sweden). }\end{array}$ \\
\hline Secondary & $\begin{array}{l}\text { Continuous }{ }^{\star} \text { CFC application } \\
\text { after } 2 \text { or more large joint } \\
\text { hemarthrosis*, but before chronic } \\
\text { arthropathy documented clinically } \\
\text { and/or by image. }\end{array}$ & $\begin{array}{l}\text { Reduce risk and frequency of } \\
\text { bleeding, development of target } \\
\text { joint and/or arthropathy; maintain } \\
\text { an adequate level of quality of life. } \\
\text { Allow physical activity. }\end{array}$ & $\begin{array}{l}\text { Controlled clinical trial (ESPRIT }{ }^{30} \text { ); } \\
\text { Prospective controlled (orthopedic study } \\
\text { of prognosis); } \\
\text { Cohorts; Retrospective (Sweden, } \\
\text { Holland, Germany, USA, United } \\
\text { Kingdom) and comparative (France vs. } \\
\text { Holland and Sweden). }\end{array}$ \\
\hline Tertiary & $\begin{array}{l}\text { Continuous }{ }^{\&} \text { CFC application after } \\
\text { chronic arthropathy documented } \\
\text { clinically and by simple } \\
\text { radiographs. }\end{array}$ & $\begin{array}{l}\text { Reduce frequency of bleeding } \\
\text { and stop or delay progression of } \\
\text { arthropathy; improve quality of life; } \\
\text { prevent risk of bleeding due to } \\
\text { comorbidities. Pain control, allow } \\
\text { physical therapy and/or orthopedic } \\
\text { surgeries. Improve quality of life } \\
\text { and physical activity. }\end{array}$ & $\begin{array}{l}\left.\text { Controlled clinical trial (SPINART }{ }^{29}\right) \text {; } \\
\text { Long-term prospective }\left(\text { POTTER }^{31}\right) ; \\
\text { Retrospective cohort (United Kingdom, } \\
\text { Italy). }\end{array}$ \\
\hline \multicolumn{4}{|c|}{ Intermittent prophylaxis } \\
\hline $\begin{array}{l}\text { Intermittent } \\
\text { prophylaxis }\end{array}$ & $\begin{array}{l}\text { Treatment applied to prevent } \\
\text { bleeding during periods not } \\
\text { exceeding } 45 \text { weeks/year. } \\
\text { Rehabilitation cases, trips, } \\
\text { trainings. }\end{array}$ & $\begin{array}{l}\text { Prevention of bleeding for short } \\
\text { periods of time }\end{array}$ & \\
\hline $\begin{array}{l}\text { ¿Continuous application: intenc } \\
\text { *Large joints: ankles, knees, hit } \\
\text { Adapted from Diagnóstico y tra } \\
\text { Coppola et al., } 2014^{32} \text { and Vale }\end{array}$ & $\begin{array}{l}\text { give treatment for } 52 \text { weeks/year and receive } \\
\text { houlders, and elbows. } \\
\text { niento hemofilia Ay B en población > de } 16 \text { al } \\
\text { no et al., 201433. }\end{array}$ & $\begin{array}{l}\text { t least } 45 \text { weeks ( } 85 \% \text { ) a priori. } \\
\text { os del segundo y tercer nivel de a }\end{array}$ & inuto Mexicano ael seguro so \\
\hline
\end{tabular}

3/week showed that patients who started prophylaxis $\leq 3$ years of age had a lower incidence of all bleeding and hemarthrosis of 0.35 and 0.12 events per patient per month, respectively, compared to patients who started after 3 years of age (0.62 and 0.25$)$. The impact on joint health was important, since it was documented that none of the patients who started early prophylaxis presented radiological data of arthropathy using the Pettersson scale, compared to $46 \%$ who started after 3 years. Even in patients who received FVIII on-demand, a lower degree of arthropathy (57\% vs. $85 \%$ ) was demonstrated with the early start of substitution therapy not only in children under but also over 3 years of age ${ }^{30}$.

Verma study, using very low prophylactic doses of FVIII (10 IU/Kg 2 days/week), documented a reduction in hemorrhagic events in children $<3$ years with only five bleeds compared to 19 in those $\geq 3$ years of age during a study follow-up of 11.5 months, with total hemarthrosis of 0 versus 11 , which represents an index per month of 0 and 0.15 in children under and over 3 years of age, respectively ${ }^{35}$.

\section{Individual prophylaxis}

There is no single parameter to evaluate the behavior or "hemorrhagic phenotype" of each patient. The annualized bleeding rate (ABR) represents a clinical parameter for measuring bleeding events and is recognized as an indicator of good response to prophylactic treatment ${ }^{36}$, combined with studies of coagulation factor pharmacokinetics ${ }^{37,38}$. The challenge is to identify patients who can benefit from low-dose CFC prophylaxis without compromising joint well-being and quality of life. Prophylactic treatment regimens are divided into two: (1) regimens with established doses of 
Table 14. Primary prophylaxis regimens

\begin{tabular}{|c|c|c|c|}
\hline Regimen & CFC dose & Advantages & Disadvantages \\
\hline $\begin{array}{l}\text { Swedish (Malmö) } \\
\text { High dose }\end{array}$ & $\begin{array}{l}\text { FVIII: } 25-40 \mathrm{IU} / \mathrm{Kg} / 48 \mathrm{~h} \\
\text { FIX: } 25-40 \mathrm{IU} / \mathrm{kg} / 2 \text { weeks }\end{array}$ & $\begin{array}{l}\text { Ensures level of CFC } \geq 1 \% \\
\text { Reduces AJBR } \sim 1 \\
\text { Ideal for patients with physical activity }\end{array}$ & $\begin{array}{l}\text { High cost } \\
\text { Low adherence; } \\
\text { Need for central venous access }\end{array}$ \\
\hline $\begin{array}{l}\text { Dutch (Utrecht) } \\
\text { Intermediate doses }\end{array}$ & $\begin{array}{l}\text { FVIII: } 15-25 \mathrm{IU} / \mathrm{kg} / 2-3 / \text { weeks } \\
\text { FIX: } 30-50 \mathrm{IU} / \mathrm{kg} / 1-2 \text { weeks }\end{array}$ & $\begin{array}{l}\text { Reduces AJBR } 1-2 \\
\text { Lower cost than high doses } \\
\text { Suitable for adults }\end{array}$ & $\begin{array}{l}\text { Sub-treatment in some patients } \\
\text { Results slightly worse in MSS }\end{array}$ \\
\hline $\begin{array}{l}\text { Canadian } \\
\text { Staggered doses* }\end{array}$ & $\begin{array}{l}\text { FVIII: } \\
50 \mathrm{IU} / \mathrm{kg} / 1 \text { week } \\
30 \mathrm{IU} / \mathrm{kg} / 2 \text { weeks } \\
25 \mathrm{IU} / \mathrm{kg} / 48 \mathrm{~h}\end{array}$ & $\begin{array}{l}\text { Allows for infusion training } \\
\text { Intermediate cost }\end{array}$ & $\begin{array}{l}\text { Depends on hemorrhagic events for dose } \\
\text { adjustment Long-term effect on MMS }\end{array}$ \\
\hline Low doses & 10-15 IU/kg 1-2/weeks & $\begin{array}{l}\text { Lower cost } \\
\text { Greater coverage of the number of } \\
\text { PwH }\end{array}$ & $\begin{array}{l}\text { Long-term effect on MMS } \\
\text { unknown, probably worse than other } \\
\text { regimens }\end{array}$ \\
\hline
\end{tabular}

CFC (high, intermediate, low, or staggered doses) and (2) the regimens adapted to the needs of the patient ${ }^{37}$. Table 14 lists the various primary prophylaxis regimens with their advantages and disadvantages $27,36,40$.

Second treatment option recognizes many differences between $\mathrm{PwH}$ and offers CFC application adapted to individual needs ${ }^{28}$, considering the following characteristics:

(a) Hemorrhagic phenotype: considers the heterogeneity of $\mathrm{PwH}$ (not only by pharmacokinetic studies) that contributes to bleeding and functional state of the musculoskeletal system; adapts the therapy according to stages of life (e.g., decrease in prophylactic dose in adulthood due to decreased physical activity). The drawback is that it relies on the presence of bleeds to define a phenotype and establish prophylaxis.

(b) Physical activity: recognizes the need for intense prophylaxis in those $\mathrm{PwH}$ with high levels of physical activity. However, it does not consider other variables that may favor bleeding and the effect on the musculoskeletal system. Changing the pattern of physical activity makes it difficult to adjust the prophylactic dose.

(c) Pharmacokinetics: scientifically calculates the patient's prophylactic regimen to obtain trough levels in a certain parameter without need to establish prophylaxis according to the bleeding phenotype. It has the disadvantage of requiring pharmacokinetic studies (multiple punctures) and the expertise of the doctor to interpret the results. It may result in supra or subtherapeutic treatment, since patients may require different trough levels for successful prophylaxis and does not consider the patient's pattern of activity.

\section{Consensus recommendation}

All patients diagnosed with hemophilia in childhood must start primary prophylaxis with application of plasma-derived coagulation factor in those who have never been exposed to any CFC, 2-3 times/week, depending on the availability of the product.

\section{Changes in lifestyle and special situations}

\section{Physical activity}

Exercise should be encouraged to maintain adequate physical fitness and musculoskeletal stability, with an emphasis on strengthening muscles, coordination, and maintaining healthy weight, which impacts on improved self-esteem and quality of life. The practice of sports or activities that do not involve physical contact is recommended, such as walking, swimming, golf, badminton, archery, cycling, rowing, sailing, and table tennis, with prophylactic administration of CFC before the activity. It is suggested to avoid high contact and impact sports such as soccer, hockey, rugby, 
boxing and wrestling, as well as high-speed activities such as motocross racing and skiing.

Before starting any physical activity, whatever sport or recreational, PwH must be evaluated by a musculoskeletal or rehabilitation specialist with experience in hemophilia, with the aim of assessing whether physical activity is appropriate, recommending necessary protection, physical conditioning required before the start of the activity and, in collaboration with the hematologist, planning the prophylactic administration of CFC. Patients with musculoskeletal dysfunction should perform weight-bearing exercises that promote the development and maintenance of adequate bone density.

\section{Immunizations}

$\mathrm{PwH}$ must follow immunization schedule according to age and health system of each country. The WFH suggests, if possible, subcutaneous administration; in case of intramuscular administration, recommendations are as follows:

- Apply after a prophylactic dose of CFC;

- Place an ice pack at the injection site for $5 \mathrm{~min}$ before application;

- Use a smallest needle possible caliber (25-27 G), and

- Compression for 5 min after application.

Live-attenuated virus vaccines such as oral polio or triple viral (MMR) vaccines may be contraindicated in $\mathrm{PwH}$ and HIV infection; however, they should receive pneumococcal and influenza vaccine each year. Immunization against hepatitis $A$ and $B$ is convenient in $\mathrm{PwH}$ and limited utility in people with HIV infection. Vaccination had previously been indicated as "danger signal" for inhibitor development. However, it has been shown that it does not increase inhibitor risk ${ }^{41}$.

\section{Medicines}

The use of drugs that affect platelet function, such as acetylsalicylic acid (ASA) and nonsteroidal anti-inflammatory drugs (NSAIDs), should be avoided, except for certain COX-2 inhibitors. The use of pain relievers such as acetaminophen is a safe alternative (Table 10) ${ }^{21}$.

\section{Dental care}

Patients must be educated on proper oral hygiene, brushing 3 times a day with a medium hard bristle brush, using fluoride toothpaste according to age, as well as flossing or interdental brushing to prevent the formation of caries and periodontal disease. Some procedures do not require CFC prophylaxis such as dental examination, the application of fissure sealants, and/or small restorations without anesthesia.

For invasive procedures requiring local anesthesia with intrapapillary and intraligamentary infiltration, the hematologist should indicate prophylactic application of CFC, DDAVP in case of mild hemophilia and/or the use of a local antifibrinolytic. It is recommended that these procedures be performed at a hemophilia treatment center.

\section{School life}

The hematologist must issue the recommendations and general care for $\mathrm{PwH}$ at school level (preferably by means of a document) to parents, and they, in turn, must inform the school personnel and classmates, to prevent activities with high risk of bleeding and ensure immediate care in case of bleeding or trauma.

\section{Adolescence}

This age group requires more intervention and attention from the multidisciplinary team of $\mathrm{PwH}$ care, in particular from the psychological evaluation standpoint due to risk of non-adherence to treatment, depression and adaptation difficulties, as well as age-specific changes, such as physical and sexual activity, among others.

\section{Sex life}

The potential hemorrhagic complications associated with sexual activity in $\mathrm{PwH}$ are related to the degree of arthropathy and limitation of movement, such as hemorrhage of iliopsoas muscle, therefore, gentle movements and/or alternate pleasurable maneuvers are recommended. Similar to general population, $\mathrm{PwH}$ may suffer from sexual dysfunction, therefore, use of low doses of short half-life 5-phosphodiesterase inhibitors (sildenafil or vardenafil) can be assessed due to the possibility of epistaxis due to nasal congestion and inhibition of platelet aggregation in vitro. Viral infections such as HIV and/or HCV have a negative impact on sexual activity because of fear for transmission to the partner, due to the disease itself, or due to the secondary effects of the treatment (reduced libido or erectile dysfunction) ${ }^{42}$. 


\section{Hemophilia in the geriatric patient}

Life expectancy of PwH has increased significantly in recent decades through advances in treatment and prophylaxis, representing a challenge for treating physician as the comorbidities of advanced age appear. These are described, in general terms, below ${ }^{43}$ :

- Systemic arterial hypertension: some observational studies have shown that the mean arterial pressure in $\mathrm{PwH}$ is higher than controls in the general population. Therefore, their risk of suffering systemic arterial hypertension is higher. Similarly, it has been observed that they require a greater concentration of antihypertensive drugs to maintain normal blood pressure.

- Diabetes mellitus (DM): in a cohort of $294 \mathrm{PwH}$ in Canada, a prevalence of DM of $9.9 \%$ was reported; however, no large-scale analysis figures are available. The adult $\mathrm{PwH}$ requires metabolic control and monitoring, like the general population, and in the case of confirmed DM, the same guidelines applicable to the local population should be used. In the case of subcutaneous insulin application, there is no significant risk of bleeding.

- Obesity: in PwH with sequelae due to hemophilic arthropathy, physical activity is limited, which increases the rate of obesity in most cases. In this group of patients, the intervention of specialized physiotherapists is necessary to increase physical activity as well as the support of nutritionists. In $\mathrm{PwH}$ without joint or muscle complications, maintain an adequate body mass index through periodic low-impact physical activity ${ }^{44}$ coupled with prophylaxis is recommended.

- Cardiovascular diseases (CVD): an increase in thrombotic vascular diseases has been observed in hemophiliacs, theoretically related to CFC use. However, some publications indicate that most cardiovascular events occur in mild or moderate $\mathrm{PwH}$, suggesting apparent protection in severe hemophilia, which so far is controversial. The risk factors for atherosclerosis are the same as those for the general population (hyperlipidemia, smoking, metabolic syndrome, hypertension, and chronic kidney disease). General recommendations for the management of acute coronary syndrome (ACS) are replacement therapy with CFC, preferably by continuous infusion, maintaining levels between 30 and $60 \%$ to be able to use anticoagulants and/or antiplatelet agents. In case of invasive procedures such as catheterization, access through the radial artery is recommended, keeping CFC activity levels at $80 \%$ for at least $48 \mathrm{~h}$ after the procedure. Low doses of ASA $(100 \mathrm{mg})$ or doubling antiplatelet agents can be used as antithrombotic prophylaxis after ACS, generally for 2 weeks and maintaining trough CFC levels at $30 \%$.

\section{Childbirth in women hemophilia carriers}

Carriers with low levels of clotting factor should be considered as $\mathrm{PwH}$ and receive appropriate treatment according to severity. During pregnancy, there is a physiological increase in factor VIII, but no change in factor IX levels, so it is recommended to measure the activity of factors during the third trimester of pregnancy with the goal of planning for replacement therapy if the levels are below $50 \mathrm{lU} / \mathrm{dL}$. Childbirth with normal fetuses will be performed according to obstetric conditions. In case of suspicion or confirmation of a product with hemophilia, the risk of trauma must be minimized by avoiding the use of forceps or suction cups during vaginal delivery, as well as invasive procedures for the fetus, such as blood draws and/or placement of internal electrodes on the scalp.

\section{Complications}

\section{INHIBITORS}

The most serious complication related to application of CFC is development of inhibitors against the deficient factor. Inhibitors are polyclonal alloantibodies that neutralize the activity of the infused FVIII or FIX. They are G-type immunoglobulins (IgG), mostly of the IgG 4 subtype, which do not fix complement and are mainly directed towards antigenic sites in the A2 and/ or $\mathrm{C} 2$ domains of factor VIII, in case of $\mathrm{HA}^{45}$.

Inhibitors are quantified in $\mathrm{BU}$, which are defined as the ability of the patient's plasma to neutralize the clotting factor in a normal plasma pool. They are classified into high-responding titers with levels $\geq 5 \mathrm{BU}$ and low-responding titers between the cutoff point of 0.6 and $5 \mathrm{BU}$. Detection of clinically significant inhibitor should be performed using the modified Bethesda-Nijmegen technique and quantified twice within an interval of 1-4 weeks, level $\geq 0.6 \mathrm{BU}$ and associated with factor recovery $<66 \%$ in a sample of blood obtained $10-15 \mathrm{~min}$ after the factor is administered. To 
avoid false-negative results and detect low-responding inhibitors, a "flushing" period is recommended, which consists of waiting 48 or $72 \mathrm{~h}$ for FVIII or FIX, respectively, between last CFC infusion and taking the blood sample. If this is not possible, "pre-heating," the patient's plasma sample is suggested to eliminate the residual factor. Low-responding inhibitors that disappear or decrease below the significant threshold within a period of 6 months from their detection and despite continuous exposure of CFC are called transient and usually do not modify the hemorrhagic phenotype of $\mathrm{PwH}^{9,12}$.

Inhibitors cumulative incidence in severe $\mathrm{HA}$ is around $30 \%$. In PUP, $79 \%$ develop within the first 20 $\mathrm{ED}$, the remaining $21 \%$ during $75 \mathrm{ED}^{12}$, with a significant difference between recombinant CFC and plasma derivatives that will be discussed later. In case of severe $\mathrm{HB}$, cumulative incidence is $4-5 \%$, with an average occurrence between 9 and $11 \mathrm{ED}$ and without difference between recombinant products and plasma derivatives. The clinical manifestations of $\mathrm{PwH}$ with inhibitors are suboptimal response for bleeding control, according to clinical criteria or as expected from previous responses to factor replacement in the same patient, with greater morbidity and musculoskeletal complications. Therefore, the presence of inhibitor should be suspected in the event of CFC refractory bleeding episode(s) at an appropriate dose, particularly in patients with severe hemophilia.

\section{RISK OF INHIBITORS}

Development of inhibitors against FVIII is a complex mechanism of interaction between genetic (non-modifiable) and non-genetic or environmental (modifiable) risk factors ${ }^{46-48}$ which are described in table 15.

\section{Genetic factors}

Among the various genetic risk factors for the development of inhibitors in HA, the most robust is type of genetic mutation. Mutations that completely prevent FVIII synthesis have an increased risk of developing inhibitors (prevalence $>30 \%$ ). These can be large deletions and nonsense mutations, with odds ratio (OR) of 3.6 and 1.4 , respectively. In contrast, mutations that produce dysfunctional FVIII without total loss of synthesis have lower risk: splicing abnormalities present an OR of 0.95; while risk for small deletions/insertions and missense mutations is 0.5 and 0.3 , respectively,
Table 15. Risk factors for the development of inhibitors

\begin{tabular}{|c|c|}
\hline $\begin{array}{l}\text { Related to the patient } \\
\text { (genetic and non-modifiable) }\end{array}$ & $\begin{array}{l}\text { Related to treatment } \\
\text { (environmental and modifiable) }\end{array}$ \\
\hline Type of mutation in F8 & Number of days of exposure \\
\hline Ethnicity & Age of first exposure \\
\hline $\begin{array}{l}\text { Polymorphisms in genes that } \\
\text { modify the immune response } \\
\text { (IL 10, TNF- } \alpha \text {, and CTLA4) }\end{array}$ & $\begin{array}{l}\text { Type of coagulation factor } \\
\text { concentrate }\end{array}$ \\
\hline Family history & $\begin{array}{l}\text { Intercurrent infection/inflammatory } \\
\text { status }\end{array}$ \\
\hline Severity of hemophilia & Intensive exposure to FVIII \\
\hline
\end{tabular}

Table 16. Classification of F8 gene mutations associated with risk of developing inhibitors

\begin{tabular}{|l|l|l}
\hline High risk & Intermediate risk & Low risk \\
\hline - Large insertions/ & - Large insertions/ & - Small insertions/ \\
deletions & deletions & deletions \\
(multiple exons) & (single exon) & - Missense \\
- Light chain & - Heavy chain nonsense & mutations \\
nonsense & mutations & - Splicing \\
mutations & - Inversion of intron 22 & mutations \\
& - Inversion of intron 1 & \\
& &
\end{tabular}

Taken from Garagiola et al., $2018^{49}$.

with an inhibitor prevalence $<10 \%$. Considering these aspects review by Garagiola classifies F8 genetic mutations as high, intermediate, and low risk for the development of inhibitors ${ }^{49}$ (Table 16).

Other genetic factors involve ancestry, genetic profile of immune response, and family history. Miller et al. ${ }^{7}$ reported a 2-fold higher frequency of inhibitors in PwH A of African and Hispanic descent compared to Caucasians $(37.1 \%, 46.9 \%$, and $19.6 \%$, respectively), without finding differences between mutation profile in these populations. Since the spectrum of mutations in F8 does not differ between ethnic groups, the difference could be based on specific genetic variants of each population, such as regulatory regions of cytokine genes that could modify profile of the immune response. Polymorphisms have been reported in a number of genes (IL1b, IL4, IL10, TNF- $\alpha$, and $C T L A^{4}$ ) that have a significant relationship with the development of inhibitors. However, association of these genetic factors is still controversial due to low reproducibility of the studies, the different genetic profiles of the analyzed populations, and the reduced 
number of cases in cohort studies ${ }^{49}$. Finally, family history of inhibitor development gives an absolute risk of $48 \%$ for this complication.

In $\mathrm{HB}$, low proportion of inhibitors is related to the smaller size of FIX molecule, 461 amino acids (AA) compared to FVIII (2332 AA), lower number of exons (eight), and high frequency of low-risk genetic mutations for the development of inhibitors (nonsense, missense, and splicing mutations) that cause production of a non-functional, but immunologically detectable protein in $\mathrm{PwH}$ B. PwH B that develops inhibitor has a tendency to exhibit an anaphylactic reaction to $\mathrm{FIX}^{50}$ due to the rapid diffusion of FIX to the extravascular space (because of its smaller size) and the need for a greater amount of CFC due to a higher physiological requirement of FIX of $5 \mu \mathrm{g} / \mathrm{ml}$ compared to FVIII of $0.1 \mu \mathrm{g} / \mathrm{ml}^{47}$.

Causal mutations in hemophilia have been compiled and are freely available on internet through the European Association for Haemophilia and Allied Disorders page at http://www.factorviii-db.org/ and http:// www.factorix.org/ for $\mathrm{HA}$ and $\mathrm{HB}$, respectively.

\section{ENVIRONMENTAL FACTORS}

There are many environmental risk factors that can contribute to the development of inhibitors: type of FVIII used (plasma vs. recombinant), those related to the application of CFC (age of first infusion, type, and intensity of treatment), and the infusion associated with warning or alarm signs. Peyvandi and Garagiola review summarizes the conclusions of the main publications regarding risk factors for the development of inhibitors in PwH A and highlighting type of FVIII product as the main environmental risk factor (Fig. 10) ${ }^{51}$.

Theory behind danger signs model, published in 1994, is based on the concept of exogenous factor exposure in a "dangerous immune environment," in which immune system is activated by warning signs (severe bleeding, surgery, trauma, vaccination, and infections). The foreign protein, in this case CFC, is presented in an intense manner (high doses and/or prolonged treatment) in conjunction with signals that activate $T$ and $B$ lymphocytes, such that, exposure to exogenous factor alone may not be enough for the development of inhibitors ${ }^{46}$. Retrospective studies in PUP, CANAL ${ }^{52}$ (Concerted Action on Neutralizing Antibodies in severe haemophilia $A$ ), and $\operatorname{RODIN}^{53}(\boldsymbol{R e}$ search Of Determinants of INhibitor development) documented that treatment with high doses of FVIII

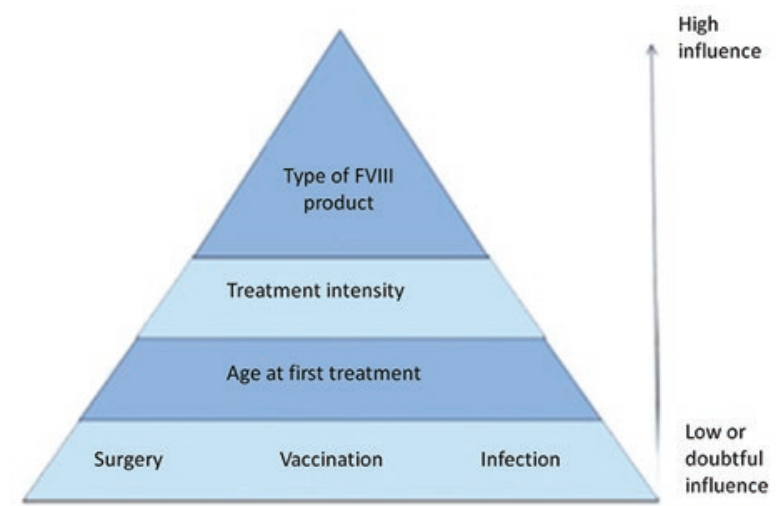

Figure 10. Environmental risk factors for the development of inhibitors in severe hemophilia A. Taken from Peyvandi and Garagiola, $2018^{47}$. Taken from Peyvandi F and Garagiola I., 2018. ${ }^{51}$

during surgeries or bleeding events increased rate of inhibitors and that prophylactic doses decreased the risk of inhibitor, especially in cases of low genetic risk after $20 \mathrm{ED}$, regardless of dose used ${ }^{53}$.

\section{Role of CFC types on the deVElopment of INHIBITORS}

Introduction of recombinant factor VIII concentrates ( $\mathrm{rFVIII)}$ in early 1990s increased cumulative risk of inhibitor development in PUPs by $25-30 \%$, mainly within first $50 \mathrm{ED}$, with an overall risk of up to 1.6; $95 \%$ Cl 1.08-2.37 for the $2^{\text {nd }}$ generation full chain FVIIIr compared to the $3^{\text {rd }}$ generation ${ }^{54}$. Retrospective, review, and meta-analysis studies suggest a difference in incidence of inhibitor development between plasma-derived factor VIII (pdFVIII) and $\mathrm{rFVIII}^{55}$, but have been criticized for their methodological biases. In 2016, the prospective randomized study SIPPET ${ }^{56}$ (Study on Inhibitors in Plasma-Product Exposed Toddlers) was published, which compared development of inhibitors between pdFVIII with von Willebrand factor and $\mathrm{rFVIII}$ in PUP under 6 years old with severe HA. Four brands of pdFVIII with von Willebrand factor (Alphanate and Fanhdi [fvW: FVIII 1], Emoclot and Factane [fvW: fVIII $\sim 0.5$ ]) and four rFVIII products (Recombinate, Kogenate FS, Advate, and ReFacto AF) were used, without intention of analyzing difference between various commercial products. Cumulative incidence for all types of inhibitors was $26.8 \%$ for pdFVIII and $44.5 \%$ with $\mathrm{rFVIII}$ and for high-responding inhibitors was $18.6 \%$ and $28.4 \%$, respectively, documenting a significantly higher incidence of $87 \%$ for rFVIII. Some authors do not accept published results and have criticized methodological aspects on 
SIPPET study, such as inhibitor cutoff, follow-up $<50$ $E D$ in a subgroup of population, high-risk mutations in a high proportion of patients who received rFVIII, $50 \%$ of patients on-demand, majority of patients from Egypt, India, and Iran, and an irregular allocation of the group of patients who received rFVIII (only 16\% used the $3^{\text {rd }}$ generation).

Publications after SIPPET study (post hoc) have shown that patients treated with rFVIII have a 3-4-fold increased risk of inhibitor development compared to pdFVII, with no significant difference using bivariate analysis models among confounding variables such as age, type of mutation, treatment center, family history, previous exposure to blood products, and registration of censored cases $(n=35)$. All inhibitors presented before $39 \mathrm{ED}$ (those with a high response $\leq 34 \mathrm{ED}$ ) and $90 \%$ before $20 \mathrm{ED}$, with an overall and high response inhibitors development risk in the first 5 ED of 3.14 (Cl: 95\%, 1.01-9.74) and 4.19 (Cl: 95\%, 1.18-14.8), respectively ${ }^{57-60}$.

Knowledge of risk factors for developing inhibitors allows designing an individualized treatment scheme to minimize this potential complication using the following strategies:

- Genetic counseling for family members with a history of inhibitors.

- Early age to start prophylaxis (usually at the end of the vaccination schedule, after 1 year):

- Avoid extravasation of factor,

- Delay elective surgeries,

- Administer pdFVIII in the first 50 ED.

Recommendations for monitoring inhibitors in $\mathrm{PwH}$ have been issued on table $17^{12}$.

\section{Consensus Recommendation:}

- Carry out an intentional search for inhibitors in PUP or minimally treated patients at 20,50, 100, and 150 ED.

- Carry out an intentional search for inhibitors in PTP, in case of changes in the hemorrhagic phenotype and/or before scheduled surgeries.

\section{Inhibitor treatment}

Treatment of $\mathrm{PwH}$ and inhibitors represents a challenge for physician, especially those that are high responding, due to higher morbidity-mortality associated with bleeding, and the high cost of care. Therapeutic strategies are divided into three groups:

- On-demand treatment for bleeding episodes,

- Prophylaxis with bypassing agents, and

- Immunotolerance treatment.
Table 17. Recommendations for inhibitor testing

After initial factor exposure, at least every 6-12 months, and annually thereafter

After intensive factor exposure (e.g., daily exposure $\geq 5$ consecutive days) and within 4 weeks of the last infusion

For recurrent bleeding or target joint bleeds, despite adequate CFC replacement therapy

For failure to respond to adequate CFC replacement therapy

For lower than expected factor recovery or half-life after CFC replacement therapy

For suboptimal clinical or laboratory response to CFC replacement therapy

Before surgery

For suboptimal post-operative response to CFC replacement therapy

For patients with hemophilia B who develop an allergic reaction to FIX therapy, including anaphylaxis or nephrotic syndrome

CFC: coagulation factor concentrate.

Taken from Srivastava, et al., $2020^{12}$.

\section{On-demand treatment for bleeding episodes}

Treatment of bleeding episodes in $\mathrm{PwH} \mathrm{A}$ and B with inhibitors will depend on inhibitor titer (low or high responding) and severity of bleeding. Patients with low-responding inhibitors and minor bleeding should receive higher than usual doses of CFC (50-100/U/kg day) for approximately 2-3 days until bleeding is controlled, monitoring clinical response (and/or deficient factor levels, with the goal of maintaining concentrations $>50 \%$ ). The National Hemophilia Foundation recommends calculating CFC dose between 25 and $40 \mathrm{IU} / \mathrm{Kg} / \mathrm{BU}$ in cases of low-responding inhibitor, thereby neutralizing the inhibitor and obtaining hemostatic levels to control bleeding. For severe bleeding, the deficient CFC dose will be calculated at $100 / \mathrm{U} / \mathrm{kg}$ day, with clinical monitoring and/or with deficient factor levels to guarantee levels above $50 \%$. If adequate response is not achieved in patients with low-responding inhibitor, they should be managed as patients with high-responding inhibitors.

The ideal management of bleeding in $\mathrm{PwH}$ with a high-responding inhibitor is using bypassing agents, of which there are two products on the market: recombinant activated factor VII (rFVIIa) and factor VIII anti-inhibitor coagulant complex, commonly known as aPCC. Table 18 shows some relevant characteristics of each component and relevant information from the technical data sheets endorsed by COFEPRIS in Mexico. 
Table 18. Characteristics of bypassing agents

\begin{tabular}{|c|c|c|}
\hline $\begin{array}{l}\text { Generic name } \\
\text { (Brand name) }\end{array}$ & Eptacog alfa activated (NovoSeven) & $\begin{array}{l}\text { Factor VIII anti-inhibitor coagulant complex activity } \\
\text { (FEIBA*) }\end{array}$ \\
\hline Content & Recombinant activated FVII & $\begin{array}{l}\text { Mainly non-activated factors II, IX, and X, and activated } \\
\text { FVII; maximum concentration of AgFVIII of } 0.1 \mathrm{UI} / \mathrm{FU}^{\&}\end{array}$ \\
\hline Formulation & $\begin{array}{l}\text { Lyophilized and diluent with histidine and water: } 1 \mathrm{mg} \\
(1 \mathrm{ml}), 2 \mathrm{mg}(2 \mathrm{ml}) \text {, and } 5 \mathrm{mg}(5 \mathrm{ml})\end{array}$ & $\begin{array}{l}500 \text { and } 1000 \text { FU with } 20 \mathrm{ml} \text { injectable water as diluent, } \\
80 \mathrm{mg} \text { of sodium per vial }\end{array}$ \\
\hline $\begin{array}{l}\text { Storage and } \\
\text { conservation }\end{array}$ & $\begin{array}{l}\text { Store below } 30^{\circ} \mathrm{C} \text {, protected from light. Do not freeze. } \\
\text { After reconstituting, chemically and physically stable } \\
\text { for } 6 \text { h at } 25^{\circ} \mathrm{C} \text { and } 24 \text { h at } 5^{\circ} \mathrm{C} \text {. Use immediately due } \\
\text { to microbiologic risk. }\end{array}$ & $\begin{array}{l}\text { Store between } 2 \text { and } 8^{\circ} \mathrm{C} \text {. Do not freeze. Can be } \\
\text { conserved at no }>25^{\circ} \mathrm{C} \text { up to } 6 \text { months within the } \\
\text { expiration date. Do not refrigerate after storing at room } \\
\text { temperature. }\end{array}$ \\
\hline Administration & 2-5 min bolus & Apply in $30-45 \mathrm{~min}$. Maximum of $2 \mathrm{FU} / \mathrm{Kg} / \mathrm{min}$ \\
\hline Pharmacokinetics & Effective half-life $2-3 \mathrm{~h}$. Faster clearance in pediatric & Effective half-life $4-7 \mathrm{~h}$ \\
\hline $\begin{array}{l}\text { Contraindications and } \\
\text { precautions }\end{array}$ & $\begin{array}{l}\text { Hypersensitivity to the product or to mouse, hamster } \\
\text { or bovine proteins. Simultaneous use with activated } \\
\text { prothrombin complex concentrates. Potential } \\
\text { development of thrombosis or induction of DIC }\end{array}$ & $\begin{array}{l}\text { Hypersensitivity to the product. Myocardial infarction, } \\
\text { acute thrombosis and/or embolism, disseminated } \\
\text { intravascular coagulation (DIC) }\end{array}$ \\
\hline Antifibrinolytics & $\begin{array}{l}\text { Limited experience with concomitant use. } \\
\text { Local use in the oral cavity is feasible. }\end{array}$ & $\begin{array}{l}\text { Avoid concomitant use due to the risk of thrombosis. } \\
\text { Administration at an interval of 6-12 h later }\end{array}$ \\
\hline $\begin{array}{l}\text { Use in pregnancy and } \\
\text { lactation }\end{array}$ & $\begin{array}{l}\text { Preferable to avoid during pregnancy, limited } \\
\text { data indicate that there are no adverse effects in } \\
\text { pregnancy or fetus/neonate health. } \\
\text { Excretion in breast milk is unknown, assess risk- } \\
\text { benefit in mother and child }\end{array}$ & $\begin{array}{l}\text { Not enough information for its use. Balance potential } \\
\text { risks of thromboembolic events }\end{array}$ \\
\hline Continuous infusion & $\begin{array}{l}\text { Reports show good hemostatic response in patients } \\
\text { with inhibitors undergoing surgery }{ }^{\mathrm{F}}\end{array}$ & No studies support this recommendation \\
\hline
\end{tabular}

Both products report adequate efficacy for bleeding control between 80 and $90 \%$, regardless of the inhibitor titer and with minimal risk of thrombosis. FENOC study found no difference in efficacy for controlling hemarthrosis between the two bypassing agents ${ }^{63}$, however, there are some pertinent considerations in the clinical context:

- FEIBA contains traces of FIX and FVIII and can induce an anamnestic response during immune tolerance induction (ITI), thus the use of $r F V I I$ is recommended in these cases.

- As rFVII is a product obtained using DNA technology, its use is suggested in pediatric population that has exclusively used recombinant products.

- The short half-life of rFVII requires repetitive infusions.

In the same way as patients with low-responding inhibitors, management of bleeding in $\mathrm{PwH}$ with high-responding inhibitor will depend on the severity of bleeding. In patients with minor bleeding, a single dose of $270 \mu \mathrm{g} / \mathrm{kg}$ of $\mathrm{rFVIla}$ or $90 \mu \mathrm{g} / \mathrm{kg}$ every $2 \mathrm{~h}, 1-3$ doses, is recommended; or 50-100 IU/kg of FEIBA. In the event of an inadequate response, it should be treated as major bleeding, for which rFVlla, 90$120 \mu \mathrm{g} / \mathrm{kg}$ per dose every $2 \mathrm{~h}$, or FEIBA, $100 \mathrm{U} \mathrm{kg} / \mathrm{dose}$ every $12 \mathrm{~h}$, is recommended (without exceeding the maximum daily dose of $200 \mathrm{U} / \mathrm{kg}$ day or $100 \mathrm{U} / \mathrm{Kg}$ per dose), during the first $24-48 \mathrm{~h}$, and considering $50-75 \%$ decrease in bleeding with a dose of bypassing agent and $90 \%$ with at least three infusions. Once bleeding is controlled, dose and/or interval of application of bypassing agent can be decreased, for rFVIla every 3-6 $\mathrm{h}$.

Patients with high-responding inhibitor and no response to anyone bypassing agent, changing the drug is suggested, and only in the absence of an adequate clinical response, both factors use can be considered sequentially: FEIBA 50-100 IU/kg every $12 \mathrm{~h}$ and after 4-6 h apply rFVIla $90 \mu \mathrm{g} / \mathrm{kg}$ every $2 \mathrm{~h}$ for 2-4 doses. 
Response evaluation to treatment is through clinical monitoring. In minor bleeds, single infusion of bypassing agent may be sufficient. Correlation has been observed between clinical response and thromboelastography (TEG), and thrombin generation studies after rFVII treatment $^{64}$. However, lack of standardization makes comparative studies difficult. Study by Fernandez-Bello et al. (2017) analyzed rFVII pharmacokinetics and pharmacodynamics comparing three doses of $90 \mu \mathrm{g} / \mathrm{Kg}$ every $3 \mathrm{~h}$ and a single dose of $270 \mu \mathrm{g} / \mathrm{Kg}$ in hemophiliacs without bleeding, and suggested that the high dose induces a higher generation of thrombin compared to application of every $3 \mathrm{~h}$. Nevertheless, the latter maintains a longer thrombin activity ${ }^{65}$. Thus, decision of a high initial dose or doses every $3 \mathrm{~h}$ will depend on the bleeding event, clinical response, and medical team experience.

In the event of surgery and high-responding inhibitors in $\mathrm{PwH}$, applying rFVIIa 90-100 $\mu \mathrm{g}$ is recommended before the surgical procedure and continuing its application every $2 \mathrm{~h}$ during the first $24 \mathrm{~h}$, with an efficiency of $90-100 \%$, or FEIBA $100 \mathrm{U} / \mathrm{kg}$ every $12 \mathrm{~h}$.

Simultaneous administration of antifibrinolytics with bypassing agents is not recommended due to the risk of thrombosis, mainly in $\mathrm{PwH}$ and prothrombotic risk factors.

\section{Prophylaxis with bypassing agents}

Prophylactic treatment with bypassing agents may be considered in patients with persistent factors inhibitors and significant bleeding phenotype as: severe or life-threatening bleeding, three significant bleeds at the same site in a 6 month period, or significant bleeding that requires bypassing agent therapy more than once a month. The main objective is to prevent or delay joint damage. There is no comparative study on the effectiveness of prophylaxis between the two bypassing agents. The Spanish and UK guidelines recommend prophylaxis with rFVII before ITI, other publications suggest that both agents can be used prophylactically before or during ITI. Suggested dose is rFVIla $90 \mu \mathrm{g} / \mathrm{kg}$ once a day or aPCC $50 \mathrm{IU} / \mathrm{kg}$ on alternate days.

\section{ITI}

ITI treatment is aimed at inducing immune tolerance to the deficient factor against which the neutralizing antibody was developed, reducing bleeding events, and allowing prophylactic regimen to be reinstated. The principle of immune tolerance consists on repeated exposure of supra-physiological doses of CFC under
Table 19. Risk factors for immune tolerance induction response

\begin{tabular}{|l|c|c|}
\hline & $\begin{array}{c}\text { Characteristics } \\
\text { for } \\
\text { good prognosis }\end{array}$ & $\begin{array}{c}\text { Characteristics } \\
\text { for } \\
\text { bad prognosis }\end{array}$ \\
\hline $\begin{array}{l}\text { Age of onset ITI } \\
\begin{array}{l}\text { Maximum historical } \\
\text { inhibitor peak }\end{array}\end{array}$ & $<200 \mathrm{BU} / \mathrm{ml}$ & $>8$ year \\
\hline $\begin{array}{l}\text { Inhibitor titer pre-ITI } \\
\text { Time to reduction inhibitor } \\
\text { titer to }<10 \mathrm{BU} \text { before ITI }\end{array}$ & $<24 \mathrm{months}$ & $>24 \mathrm{BU} / \mathrm{ml}$ \\
\hline
\end{tabular}

BU: Bethesda unit, ITI: immune tolerance induction

Adopted from Brackmann et al., $2018^{64}$.

non-inflammatory conditions, with or without the concomitant use of immunosuppressive agents ${ }^{66,67}$. The first ITI therapy to eradicate inhibitor was performed in 1974 at the University of Bonn, Germany, using high doses of factor VIII of $100 \mathrm{IU} / \mathrm{kg}$ plus aPCC 2/day plus immunosuppressive treatment ${ }^{68}$. To date, several ITI schemes have been described with different doses of FVIII with international response rates of $100 \%$ for low-responding inhibitor titers (> 0.6-5 BU/ml) and between 60 and $90 \%$ for high-responding inhibitor (> $5 \mathrm{BU} / \mathrm{ml}$ ). Prognostic response factors for ITI have been known for over a decade (Table 19). A recent publication by experts on the management of HA with inhibitors, the FIT group (The Future of Immunotolerance Treatment) ${ }^{69}$ recognizes inhibitor titers before ITI as independent predictors of response, and describes four risk groups: (a) very good prognosis < $25 \mathrm{BU} / \mathrm{ml}$; (b) good prognosis 25-199 BU/ml; (c) poor prognosis 200-999 BU/ml; and (d) very poor prognosis + $1000 \mathrm{BU} / \mathrm{ml}$. They propose new lines of treatment depending on the increase of the inhibitor titer during treatment, which is beyond the scope of this document.

Successful ITI response consists of negative inhibitor titers $(<0.6 \mathrm{BU} / \mathrm{ml})$, recovery $>66 \%$, and FVIII half-life $\geq 6 \mathrm{~h}$. A partial response implies inhibitor titers $<5 \mathrm{BU} / \mathrm{ml}$ with recovery and FVIII half-life of $<66 \%$ and $6 \mathrm{~h}$, respectively. Treatment failure occurs with persistence of inhibitor $>5 \mathrm{BU} / \mathrm{ml}^{70,71}$. (2012) Randomized study by Hay et al. (2012), in patients with "good prognosis" severe HA with high-responding inhibitors, compared high doses of FVII $(200 \mathrm{IU} / \mathrm{kg} / \mathrm{d})$ versus low doses (50 IU/kg/3 times a week) without showing a significant difference in the success rate (70\% in intention-to-treat analysis). However, the time to achieve a negative titer, that is, the most frequent 
bleeding phase, was significantly shorter with highdose regimen ${ }^{72}$. In patients with an unfavorable prognosis, a higher efficacy rate for inducing tolerance was observed when administering products with FVIII containing von Willebrand compared to highly purified products. However, to date, there is no conclusive evidence from controlled clinical trials.

\section{Infections}

Transmission of HIV, HCV, and HBV between 1980 and 1990 through CFC increased morbidity and mortality of $\mathrm{PwH}$. Since implementation of better techniques for detection of transfusion-transmissible infections (TTI) and viral inactivation processes, the risk of infection has decreased. However, there is an estimated frequency between 30 and $50 \%$ of population infected in first world countries. Furthermore, it is calculated that coinfection with HIV and HCV in $\mathrm{PwH}$ increases treatment costs by $59 \%{ }^{73}$.

TTI detection methods have focused on retroviruses (HIV and human T-cell lymphotropic virus), HBV, and $\mathrm{HCV}$, revealing emerging viral infections (human herpesvirus 8, parvovirus $B 19$, and hepatitis $A$ and $E$ ). Arboviruses such as West Nile, Dengue and Chikungunya viruses, and prions (Creutzfeldt-Jakob) have recently become relevant, but there are no universal detection protocols in blood banks. The risk of TTI is latent, since $75 \%$ of world population does not have access to recombinant CFC or plasma derivatives that comply with biosecurity processes.

According to the 2018 Annual Survey, in Mexico, 45 hemophilia patients are infected with HIV and 275 with $\mathrm{HCV}$, however, the exact number of active hepatitis is unknown ${ }^{4}$.

\section{Musculoskeletal complications in hemophilia}

Hemophilic arthropathy is a variant of joint disease secondary to recurrent joint bleeding (hemarthrosis), characterized by deformity, synovial hypertrophy, and destruction of cartilage and bone. The development of hemophilic arthropathy occurs in three stages: acute hemarthrosis, chronic synovitis, and degenerative arthritis.

\section{Pathophysiology}

Pathophysiology of hemophilic arthropathy is different than the systemic or degenerative inflammatory processes such as seen in rheumatoid arthritis or degenerative osteoarthritis, respectively. Its main mechanism is triggered by release of hemoglobin and hemosiderin deposition in synovial tissue, which induces hypertrophy of the synovial membrane and neovascularization. Both processes are mediated by inflammatory cytokines such as IL-6, IL-1 $\beta$, TNF- $\alpha$, INF- $\gamma$, and IL-8, which cause chronic synovitis with formation of villi into the joint space, which are more susceptible to bleeding spontaneously or due to minimal stress, establishing a vicious cycle of rebleeding and increased synovitis. Furthermore, metabolic changes (activation of metalloproteinases) in cartilage and subchondral bone promote its destruction, with subsequent joint deformation. Complete description of mechanism of arthropathy in hemophilia consult work by Wyseure et al. (2016) ${ }^{74}$.

\section{Diagnosis}

Assessment of joint health and structural changes is made through clinical examination and imaging studies. Simple radiography can show advanced bone changes such as overgrowth of the epiphyses, narrowing of the joint space, subchondral cysts formation, and osteoporosis, but have little sensitivity to demonstrate early soft-tissue changes that occur before irreversible cartilage damage. There are two radiological classification systems: Arnold-Hilgartner scale, which assesses changes in soft tissue and bone tissue, in which the image with highest level of affection dictates arthropathy degree (Grades I to V); and Petterson scale, which excludes soft tissues and assigns score for each radiological change. This last evaluation scale is the one recommended by the WFH for its availability and affordability cost.

Simple radiography studies can only detect irreversible changes, this is why magnetic resonance imaging (MRI) is considered gold standard for diagnosis of hemophilic arthropathy identifying early (reversible) changes in soft tissues, such as integrity of cartilage, hemosiderin deposits, intra-articular fluid, and edema. Disadvantages of MRI are the need for sedation in children, cost, availability, and inability to explore multiple joints. An alternative to these drawbacks is through ultrasound (US), which, with appropriate technology, allows obtaining high-resolution images of joint anatomy, including tendons, ligaments, and muscles, representing an important auxiliary tool for detection and monitoring acute hemarthrosis, as well as for differential diagnosis between pain from bleeding 


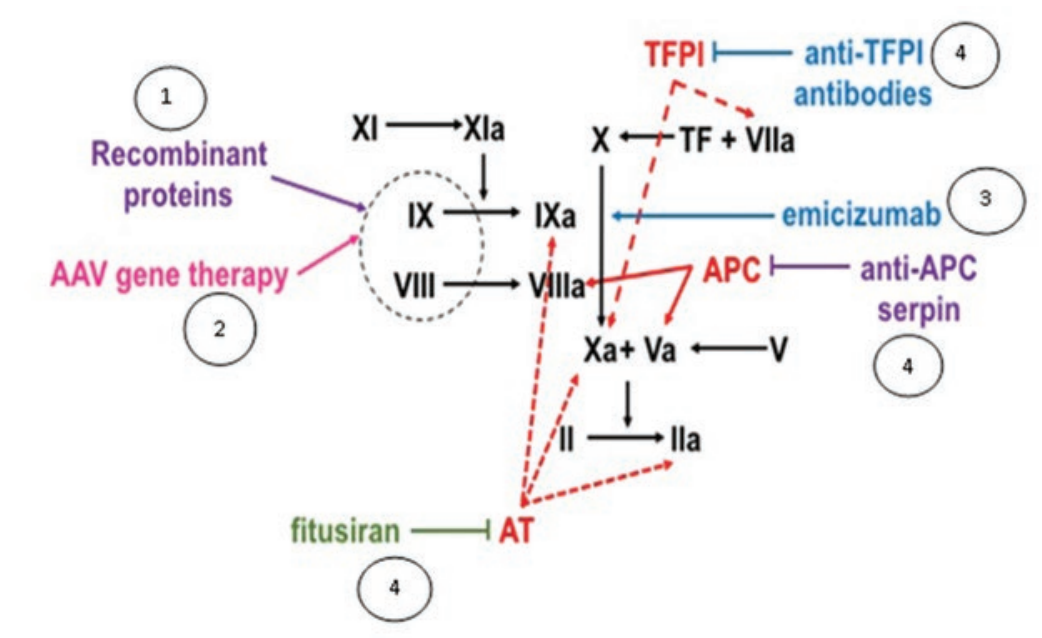

\begin{abstract}
Mechanisms of action for treatment of hemophilia. 1) rCFC with extended half-life; 2) gene therapy: 3) antibodies that simulate the function of FVIII (emicizumab), and 4) molecules that modify the action of natural anticoagulants: anti-TFPI antibodies (concizumab, BAY 1093884, BAX 499), antiAPC, AT blocking (fitusiran).

$\mathrm{AAV}=\mathrm{Adeno}-$ associated virus, $\mathrm{TFPl}=$ Tissue factor pathway inhibitor, $\mathrm{APC}=\mathrm{Activated}$ prote in $\mathrm{C}, \mathrm{AT}=$ antithrombin.
\end{abstract}

Figure 11. Mechanisms of action of emerging therapies in hemophilia. Taken and adapted from Arruda, et al., $2018^{76}$.

or from soft-tissue involvement (sprains, muscle tears, tendinitis, etc.). Lately, the US evaluation scale that assesses the synovial capsule, cartilage, and subchondral bone, called Haemophilia Early Arthropathy Detection with Ultrasound (HEAD-US), has been proposed.

The WFH recommends evaluating joint deterioration of six index joints (elbows, knees, and ankles) using the Gilbert physical examination scale, which is designed for adults and older children with established arthropathy. However, it has deficiencies such as lack of reliability, validity, and sensitivity to smaller changes in patients with less severe disease, so several modifications have been made to the system. The second clinical and functional joint scale that assesses gait, arcs of motion, muscle tone, pain, and increased volume, among other data, is performed using the Hemophilia Joint Health Score (HJHS). Depending on context of the patient and experience by multidisciplinary team, joint health scales should be applied to help diagnose chronic synovitis and guide treatment decisions ${ }^{12}$.

\section{New treatments}

\section{Introduction}

CFC replacement therapy has been effective for control and/or prevention of bleeding in $\mathrm{PwH}$ for decades; however, it is limited by accessibility and preservation of products, the relatively short hemostatic duration, and the development of complications such as appearance of neutralizing antibodies (inhibitors) against FVIII or FIX. The search for complete healing remains the final goal. With the intention of improving treatment of $\mathrm{PwH}$, products with prolonged half-life and alternative mechanism of action have been designed to achieve adequate hemostasis and reduced immunogenicity ${ }^{75}$ through: (1) CFC with extended half-life (EHL); (2) gene therapy; (3) specific antibodies that simulate the function of FVIII; and (4) molecules that modify the action of natural anticoagulants $^{76}$. These are shown in figure 11 and briefly described below:

\section{Coagulation factors with EHL}

EHL factors have the power to reduce number of infusions needed to treat episodes of acute bleeding and to extend time between prophylactic infusions, thereby allowing greater adherence to treatment schedules. Strategies to delay clearance and extend the half-life of recombinant FVIII or FIX in the intravascular space are based on artificially binding to other molecules through the following options:

- Binding to the constant fragment (Fc) of Ig;

- Pegylation, and

- Binding to recombinant albumin. 


\section{EHL FACTOR VIII}

The benefit of EHL FVIII products has been limited, with an average half-life extension of 1.5 times, which has allowed prophylactic application in adults twice a week, but with a wide range half-life between patients and shorter duration in pediatric population. Therefore, the doses should be personalized according to the bleeding phenotype and the half-lives of standard product and $\mathrm{EHL}$ factors ${ }^{77}$.

The first technology used to increase the half-life of FVIII was through fusion with IgG constant region $(\mathrm{Fc})$. Efmoroctocog alfa (Eloctate and Biogen/Sobi) is a FVIII factor analog bound to the Fc domain of human IgG1 lacking domain B.

The second option to prolong factor half-life is through covalent binding of polyethylene glycol (PEG) to FVIII (Pegylation) ${ }^{78}$. There are three Food and Drug Administration (FDA)-approved products with this technology:

- Octocog alfa (Adynovate, Shire);

- Turoctocog alfa pegol (Novoeight-GP, Novo Nordisk), and

- Damoctocog alfa pegol (DAMATO Bayer).

The third mechanism to decrease FVIII clearance is by adding negative charges through polysialic acid, which interferes with receptor-mediated clearance. The BAX826 molecule (octocog alfa, Shire) is undergoing preclinical studies.

\section{EHL FACTOR IX}

The traditional prophylaxis scheme for severe $\mathrm{PWH}$ $B$ is by infusion of FIX twice a week. Structural modifications of FIX products with EHL include, like FVIII, Pegylation, and fusion with Fc or albumin. The first EHL rFIX on the market was fused to the Fc protein (rFIX-Fc) (eftrenonacog alfa, Alprolix, Biogen/Sobi), with a half-life of $86.5 \pm 32.2 \mathrm{~h}$. Patients who received $50 \mathrm{IU} / \mathrm{kg}$ weekly achieved minimum FIX levels of 1-3 IU/dl, with a rapid decrease in the first 24-72 $\mathrm{h}$ post-infusion, followed by a longer half-life. The second FDA-approved factor is albumin-bound rFIX (rFIXFP) (albutrepenonacog alfa, Idelvion, CSL Behring), which has the advantage over rFIX-Fc pharmacokinetics of a gradual decrease following infusion, with a half-life of $104 \mathrm{~h}$. The EHL of this product is based on its high molecular weight (above the renal threshold) and a pH-dependent interaction with the neonatal Fc receptor $(\mathrm{FcRn})$, which prevents its intracellular degradation. Finally, the pegylated $\mathrm{rFIX}$ nonacog beta pegol (N9-GP), manufactured by Novo-Nordisk company, and approved by the FDA in May 2017, by the trade name REBINYN ${ }^{\circledR}$.

\section{Treatment strategies without substitute factor}

The main advantages of this treatment modality are minimizing the risk of inhibitor development, subcutaneous administration, and prolonged weekly and/or monthly application intervals. These therapies attempt to amplify thrombin generation through different mechanisms of action $^{79}$ or to increase endogenous production of deficient factor through gene therapy, as explained below.

\section{THERAPIES THAT AMPLIFY THROMBIN GENERATION:}

\section{Biospecific antibody that mimics factor VIII function}

Emicizumab, authorized by the FDA under the trade name Hemlibra (Hoffmann La-Roche), is a biospecific humanized monoclonal antibody that simulates biological function of FVIIla, establishing a procoagulant effect through its antigen-binding fragment (Fab), joining FIXa and the coagulation substrate FX on a layer of phospholipids, generating thrombin with a dose-dependent effect, and, therefore, shortening aPTT. Administration is subcutaneous, with a half-life of approximately 4-5 weeks. The authorized dose for the management of $\mathrm{PwH} A$ with inhibitors is $3 \mathrm{mg} / \mathrm{kg}$ weekly for the first 4 weeks and subsequently $1.5 \mathrm{mg} / \mathrm{kg}$ weekly or $3 \mathrm{mg} / \mathrm{kg}$ biweekly or $6 \mathrm{mg} / \mathrm{kg}$ monthly. It does not share structural homology with FVIII, except for the binding sites, so the development of inhibitors against this molecule is not expected and it is not neutralized by FVIII inhibitors ${ }^{76,80}$.

HAVEN $1^{81}$ and 2 studies evaluated $\mathrm{PwH}$ A with high-responding inhibitors, reporting a reduction in annual bleeding rate with a significant difference of $87 \%$ with weekly application of emicizumab. Based on these studies, emicizumab was approved in 2017 as prophylaxis to prevent or reduce frequency of bleeding episodes in PwH A with inhibitors directed against FVIII. It is pertinent to mention the possibility of thrombotic complications with the concomitant use of aPCC at therapeutic doses secondary to a synergism between the two substances. Since emicizumab increases enzymatic action of FIXa contained in CCP 20,000 times, therefore, its use is recommended, if necessary, at low doses. No thrombotic events associated with rFVIla or emicizumab as monotherapy are reported. 
Subsequently, in 2018, indication for emicizumab was extended to $\mathrm{PwH}$ A without inhibitors based on HAVEN 3 and HAVEN 4 clinical studies ${ }^{82}$, which showed a reduction in annual bleeding rate between 96 and 97\% compared to placebo. With this evidence, it has been suggested consider emicizumab in patients without inhibitors with difficult venous access, not candidates for central venous catheter, who require high doses of FVIII (with clinical behavior similar to patients with inhibitors) or at high risk of inhibitors development.

Agents that modify function of natural anticoagulants such as TF pathway inhibitor (TFPI), antithrombin, and activated protein $\mathrm{C}$ (APC)

\section{TFPI}

In $\mathrm{PwH}$, amplification of coagulation and thrombin generation is altered by FVIII or IX deficiency. TFPI is a serine protease that plays an important role in the initial generation of thrombin by inhibiting TF-factor VIla complex (TF-FVIla) and prothrombinase. Monoclonal antibodies and aptamers ${ }^{2}$ that inhibit TFPI function are under investigation: concizumab (Novo Nordisk): humanized IgG4 monoclonal antibody; BAY 1093884 (Bayer): humanized monoclonal antibody $\lg G 2$, and BAX 499 (Shire): aptamer of pegylated nucleic acid.

\section{Antithrombin inhibitor (Fitusiran)}

Fitusiran (Alnylam Pharmaceuticals) is an interfering ribonucleic acid (RNAi), which binds to messenger RNA (mRNA) and interrupts its production, with subsequent decrease in synthesis of antithrombin (AT) in liver. AT is the main natural anticoagulant that inactivates thrombin and FXa. Patients in dose-escalation study showed consistent and sustained drops in antithrombin levels, with subsequent increase in thrombin generation and reduction in bleeding events. Due to safety concerns, the clinical phase III (ATLAS) evaluating fitusiran once a month, included in the specified guideline reducing doses of replacement factor or bypass agent to treat any breakthrough bleed in order to prevent thromboembolic event ${ }^{79}$.

\section{Gene therapy}

Gene therapy consists of introducing sequence of specific gene into a target cell. By employing a virus

2 Single chain DNA or RNA nucleic acids with high binding specificity for a target molecule (protein) as a vector for genetic material is called transduction, which can be carried out through two conducts: (a) direct administration "in vivo" of the therapeutic gene through a vector, mainly associated with adenovirus (AAV, for its Adeno-Associated Virus) and/or (b) transplantation of cells to which the "ex vivo" gene has been inserted, using lentivirus type vectors (LV) ${ }^{83}$.

Hemophilia gene therapy uses AAV to transduce the clotting factor gene directly into hepatocytes. Some clinical trials have obtained the sustained expression of therapeutic levels of FVIII and FIX. However, it has its limitations, around $40 \%$ of population have antibodies against the capsid of one of the AAV serotypes, which limits transduction, as well as the development of a cellular-type immune response characterized by transaminitis and/or a decrease in transgenetic expression.

Current research in hemophilia gene therapy is focused on administration of AAV vectors directly to the liver intravenously and immune response controlled by high doses of steroids. Recent studies in $\mathrm{PwH} B$ suggest a potential cure for this disease.

Second part of this document reviews an acquired coagulopathy by inhibition of FVIII activity, which in recent years has become relevant in Mexico due to its impact on morbidity and mortality, clinical presentation, and its high cost of care.

\section{AHA}

$\mathrm{AHA}$ is an autoimmune disease caused by polyclonal autoantibodies subtype IgG1 and IgG4 against specific epitopes of heavy chain (domain A2) or light chain (domains $\mathrm{C} 2$ and $\mathrm{A} 3$ ) of FVIII that exerts their inhibitory effect interfering with binding to FIXa, membrane phospholipids, and VWF. AHA incidence is 0.21.48 cases per $1,000,000$ population per year. The median age of presentation is 65 years, with biphasic distribution: a small peak in women between 20 and 30 generally associated with pregnancy or collagen disease, and second peak over 60 years old, without gender predominance. Overall mortality range is broad (15-42\%) due to complications associated with older age in most cases, treatment comorbidities, and/ or therapeutic side effects ${ }^{84,85}$.

It may considered that the autoantibodies production come from a loss of peripheral immune tolerance mechanisms, consequence from genetic and environmental factors. The majority of AHA cases are idiopathic $(43.6 \%-51.9 \%)$, followed by those stemmed from neoplasms such as solid tumors (prostate or lung 
cancer), lymphoproliferative disorders (commonly lymphoma) between $6.4 \%$ and $18.4 \%$, autoimmune diseases such as rheumatoid arthritis (9.4-17.0\%), medication intake, dermatological diseases, pregnancy (usually 1-4 months postpartum), and others. Pediatric cases of $\mathrm{AHA}$ are rare, with an estimated incidence in children under 16 years old of 0.045 cases per million population per year ${ }^{86}$.

\section{Diagnosis}

AHA should be suspected in those cases that present sudden-onset bleeding, often severe, spontaneous, or after mild trauma, invasive or postpartum procedures, with no personal or family history of bleeding, and prolonged aPTT that does not correct with normal plasma pool mixing, normal hemostatic test (platelets count, PT, TT, and fibrinogen), and lupus anticoagulant (LA) negative ${ }^{87}$. The hemorrhagic pattern is different than congenital hemophilia, majority of patients present with subcutaneous ecchymosis or bruising (> $80 \%)$, muscular bleeding (>40\%), gastrointestinal bleeding (> 20\%); bleeding at genitourinary or retroperitoneal levels, postpartum, and other sites represent $<10 \%$. Often, hemorrhages are life threatening due to intensity of bleeding or involving the brain. The main laboratory finding to consider AHA is detection of prolonged aPTT that does not get corrected with normal plasma and a normal PT. Differential diagnosis of prolonged aPTT includes presence of LA or heparin effect. Incubation of patient's plasma with normal plasma $1: 1$ for $2 \mathrm{~h}$ at $37^{\circ} \mathrm{C}$ allows presence of an inhibitor to be evidenced, with a greater prolongation of aPTT due to temperature and time-dependent inactivation of FVIII. Similar prolongation of aPTT before and after incubation is indicative of LA. Unfractionated and low-molecular-weight heparins (LMWH) at therapeutic doses can prolong aPTT, however, conventional heparin also prolongs TT with a normal reptilase time; anti-factor $\mathrm{Xa}$ assays are required to rule out the effect of LMWH.

AHA confirmation is carried out by documenting low levels of FVIII activity and evidence of inhibitor quantified in BU, preferably with Bethesda-Nijmegen technique or Bethesda assay. In some centers, autoantibodies IgG anti-FVIII detection is carried out by ELISA ${ }^{84}$. Classification is similar to congenital hemophilia and depends on inhibitor levels in low $(<5 \mathrm{BU} / \mathrm{mL}$ ) or high (>5 BU/mL) titers. Figure 12 shows the diagnostic algorithm for AHA suggested by the Spanish group ${ }^{88}$.
Autoantibodies in AHA exhibit a non-linear or type 2 FVIII inactivation pattern (as opposed to type 1 kinetics caused by characteristic alloantibodies in congenital hemophilia), causing a first phase of linear inactivation, followed by an equilibrium phase or "plateau" that allows residual detection of FVIII (Fig. 13). This mechanism causes residual FVIII levels to be unreliable for predicting the risk of bleeding. Therefore, even with relatively high levels of FVIII, the risk of bleeding is relevant if inhibitor titers are high in AHA.

Type 1 inhibition kinetics of FVIII activity (Figure 13, black circles) is characteristic of alloantibodies in congenital hemophilia, it presents a linear pattern where a higher concentration of antibodies, greater neutralization capacity of FVIII. Type 2 kinetics (Figure 13, triangles). Characteristic of alloantibodies in congenital hemophilia, it presents a linear pattern where the greater the concentration of antibodies, the greater the neutralization of FVIII. Type 2 kinetics (triangles) caused by autoantibodies in acquired hemophilia shows a phase of primary linear inhibition followed by an equilibrium phase, which allows the detection of residual FVIII activity in vitro.

\section{Treatment}

Seventy to 90 AHA cases present major bleeding, thus the management of patient with AHA should be carried out immediately by personnel with experience in this pathology, or if not possible, under their advice, in centers that have sufficient resources for hemostatic factors and inhibitor monitoring and FVIII levels.

Overall goals in AHA treatment are as follows:

1. To control and prevent bleeding,

2. Inhibitor eradication, and

3. Treatment of underlying disease (if any).

\section{Control and prevention of bleeding}

Recommendation is to start hemostatic (anti-hemorrhagic) treatment in patients with AHA with symptoms of major bleeding and/or decreased hemoglobin level, regardless of inhibitor titer and FVIII levels, or prophylactically in patients at high risk of bleeding (recent surgery or delivery, peptic ulcer, etc.). Patients with mild or moderate bleeding and without significant impact on hemoglobin levels may not warrant immediate hemostatic therapy, but require close monitoring. Preventive bleeding measures involve deferring invasive procedures or surgeries until the inhibitor is eradicated and adequate FVIII levels are documented. In case of 


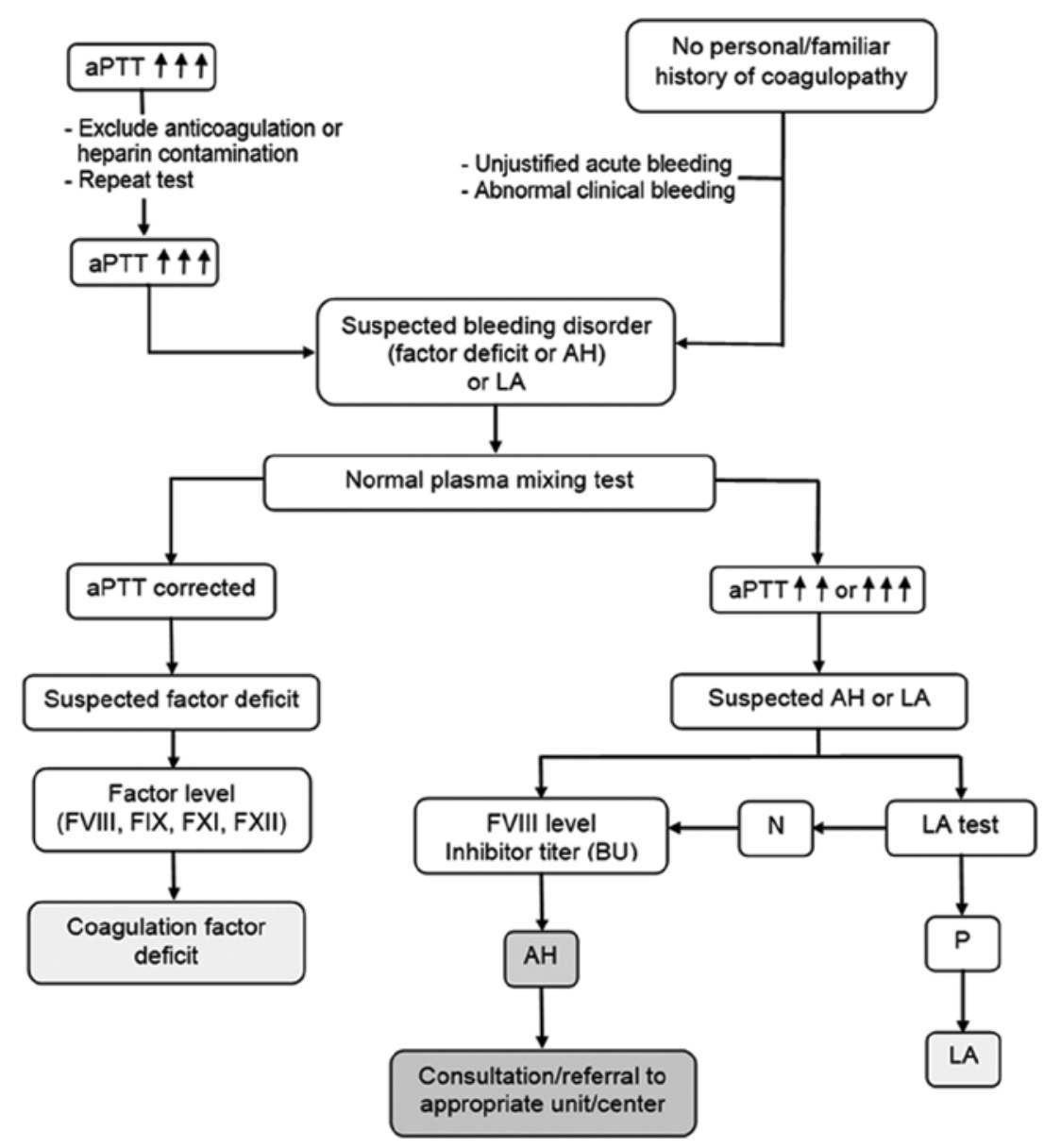

Figure 12. Diagnostic algorithm for AHA using laboratory tests. aPTT: activated partial thromboplastin time; AH: acquired hemophilia; LA: Iupus anticoagulant; FVIII: factor VIII; FIX: factor IX; FXI: factor XI; FXII: factor XII; N: negative; P: positive. Adapted from Mingot-Castellano et al., $2017^{88}$.

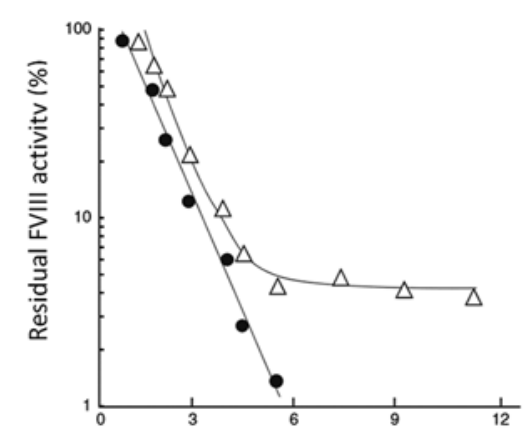

Plasma incubation time in vitro (hours)

- Type 1 inhibition kinetics $\Delta$ Type 2 inhibition kinetics

Figure 13. Kinetics of FVIII inhibition by antibodies (Taken from Mingot-Castellano, et al., 2017). ${ }^{88}$

urgent intervention, bypassing agents should be used before and after the procedure, as previously discussed. The third part of cases does not present bleeding and does not require hemostatic management.
Table 20 describes treatment alternatives for acute bleeding in $\mathrm{AHA}^{84,85,89}$.

Any of the two commercially available bypassing agents (rFVIIa and FEIBA) are the first choice of treatment for AHA bleeding. The European EACH2 (European Acquired Haemophilia) ${ }^{90}$ registry of 237 patients treated with rFVIla or FEIBA did not report a significant difference for bleeding control with response rates of 92 and $93 \%$ nor for thrombosis incidence (2.9\% and $4.8 \%$, respectively). Advantages and disadvantages of each drug (Table 21) should be assessed according to clinical context, for example, rFVIla is suggested postpartum ${ }^{85}$.

\section{Relevant considerations of hemostatic therapies in AHA}

The election of the bypassing agent will depend on availability, economic characteristics, previous efficacy (if apply), and physician experience. The outcome 
Table 20. Hemostatic treatment alternatives in AHA

\begin{tabular}{|c|c|}
\hline Agent & Observations \\
\hline $\begin{array}{l}\text { First-line treatment } \\
\text { rFVIla } \\
\text { aPCC }\end{array}$ & $\begin{array}{l}70-90 \mu \mathrm{g} / \mathrm{kg} \text { e/2-3 h until bleeding is controlled, afterward reduce dose and/or increase } \\
\text { treatment interval time. } \\
50-100 \mathrm{U} / \mathrm{kg} \text { e/8-12 h, without exceeding } 200 \mathrm{U} / \mathrm{kg} / \text { day }\end{array}$ \\
\hline $\begin{array}{l}\text { Alternative treatment (if bypass treatment is } \\
\text { unavailable) } \\
\text { pdFVIII o rFVIII }\end{array}$ & \\
\hline $\begin{array}{l}\text { Desmopressin } \\
\text { Antifibrinolytics }\end{array}$ & $\begin{array}{l}\text { Only in cases with low-responding inhibitor and/or minor bleeding. } \\
\text { Scarce evidence. Consider in minor bleeding and low inhibitor titers } \\
(<2 \mathrm{BU} / \mathrm{ml}) \text { and FVIII }>5 \% \text {. Evaluate potential secondary effects. } \\
\text { Potential usefulness for oral bleeding and contraindicated in hematuria. }\end{array}$ \\
\hline $\begin{array}{l}\text { Alternative treatment* } \\
\text { Porcine rFVIII }\end{array}$ & 100-200 U/kg initially, monitor FVIII activity to recalculate dose. \\
\hline $\begin{array}{l}\text { Second-line treatment } \\
\text { Immunoadsorption and/or plasmapheresis }\end{array}$ & Reserved for refractory hemorrhage or urgent inhibitor reduction before surgery. \\
\hline
\end{tabular}

Adapted from Franchini, et al., 2017 $217^{84}$ y Kruse-Jarres, et al., $2017^{85}$.

Table 21. Advantages and disadvantages of bypassing agents

\begin{tabular}{|c|c|c|}
\hline Agent & Advantage & Disadvantage \\
\hline $\begin{array}{l}\text { Factor VIII } \\
\text { anti-inhibitor } \\
\text { coagulating } \\
\text { complex (FEIBA) }\end{array}$ & $\begin{array}{l}\text { Proven efficacy } \\
\text { for bleeding } \\
\text { control }\end{array}$ & $\begin{array}{l}\text { No existing specific } \\
\text { laboratory monitoring. } \\
\text { Risk of arterial or venous } \\
\text { thrombosis. }\end{array}$ \\
\hline $\begin{array}{l}\text { Recombinant } \\
\text { activated factor } \\
\text { VII (rFVIla) }\end{array}$ & $\begin{array}{l}\text { Proven efficacy } \\
\text { for bleeding } \\
\text { control }\end{array}$ & $\begin{array}{l}\text { No existing specific } \\
\text { laboratory monitoring. Short } \\
\text { half-life }(2 \mathrm{~h}) \text {. } \\
\text { Risk of arterial or venous } \\
\text { thrombosis. }\end{array}$ \\
\hline
\end{tabular}

Adapted from Kruse-Jarres et al., $2017^{85}$.

to treatment is guided by clinical evaluation, usually in the first 24-72 h, depending on site, kind, and severity of bleeding. Once bleeding is controlled, dose and/or interval of administration of bypassing agent should be decreased to prevent risk of thrombosis. Zanon et al. reported that the use of prophylactic lowdose of FEIBA (mean $54.2 \pm 23 \mathrm{IU} / \mathrm{Kg}$ ) for an average of $20 \pm 17.6$ days significantly prevented rebleeding rate $^{91}$.

Alternative therapies such as DDAVP and FVIII concentrates (plasma derived or recombinant) are based on increasing FVIII levels, with a response rate of $68.3 \%$. DDAVP increases FVIII levels in an unpredictable way, representing risk factor for thrombosis in elderly patients and those with predisposing conditions (malignancy or thrombosis history).

\section{Table 22. Definitions for treatment failure in AHA}

Persistent bleeding, without changes in blood loss overtime $\mathrm{Hb}$ levels without change or reduced in spite of transfusion therapy Increase in internal bleeding size observed by imaging studies

Evidence of continuous bleeding after $48 \mathrm{~h}$ of adequate (24 h for critical anatomical sites)

Bleeding in new sites despite anti-hemorrhagic treatment Increase in pain associated with hematomas, in spite of treatment $\mathrm{Hb}$ : hemoglobin. Taken from Huth-Kühne et al., $2009^{89}$.

Hospitalized patients with risk factors for thrombosis should be considered for thromboprophylaxis and keeping the FVIII above 50\%. Bypassing agents should be avoided in patients without evidence of active bleeding or increased risk of bleeding. Antifibrinolytic drugs can be used as adjuvants topically in mouthwash and are contraindicated for a period of 12 $\mathrm{h}$ after using FEIBA. Finally, recombinant porcine factor VIII (rpFVIII) has $86 \%$ effectiveness without significant adverse events, however, it is not available in Mexico.

There is no validated laboratory parameter for monitoring hemostatic therapy, aPTT is not a good indicator of response to treatment, consolidating value of clinical evaluation. Table 22 describes criteria for treatment failure in AHA. 
Table 23. Options for first-line immunosuppression therapy in AHA

\begin{tabular}{|c|c|c|}
\hline $\begin{array}{l}\text { Recommended first-line } \\
\text { immunosuppression }\end{array}$ & Recommended dose & Comments \\
\hline Corticosteroids alone & $\begin{array}{l}\text { Prednisone } 1 \mathrm{mg} / \mathrm{kg} \text { PO daily (alternative } \\
\text { dexamethasone } 40 \mathrm{mg} \text { PO or IV } \\
\text { daily } \times 4-7 \text { days) }\end{array}$ & $\begin{array}{l}\text { Unlike to be effective } \leq 3 \text { weeks in patients } \\
\text { with FVIII }<1 \mathrm{IU} / \mathrm{dl} \text { or inhibitor }>20 \mathrm{BU} / \mathrm{mL} \text { at } \\
\text { presentation. } \\
\text { Monitor for adverse effects (elevated glucose, } \\
\text { infection, and psychiatric disorders) }\end{array}$ \\
\hline Corticosteroids and cyclophosphamide & $\begin{array}{l}\text { Corticosteroid same as above; } \\
\text { cyclophosphamide 1-2 mg/kg PO daily } \\
\text { (alternative } \sim 5 \mathrm{mg} / \mathrm{kg} \text { IV q 3-4 weeks) }\end{array}$ & $\begin{array}{l}\text { May have faster response rate than steroids } \\
\text { alone, but higher adverse event profile } \\
\text { Associated with a higher CR rate } \\
\text { Monitor for marrow suppression (white blood cell, } \\
\text { platelets) and infection }\end{array}$ \\
\hline Corticosteroids and rituximab & $\begin{array}{l}\text { Corticosteroids as same above; rituximab } \\
375 \mathrm{mg} / \mathrm{m}^{2} \text { IV weekly } \times 4 \\
(\text { alternative } 100 \mathrm{mg} \text { weekly } \times 4 \text { ) }\end{array}$ & $\begin{array}{l}\text { Rituximab is not recommended as initial } \\
\text { monotherapy unless other IST in contraindicated }\end{array}$ \\
\hline
\end{tabular}

Comments

Median time to response (FVIII activity level restored to $>50 \mathrm{IU} / \mathrm{dL}$ ) is 5 weeks. Patients with FVIII activity level $<1 \mathrm{IU} / \mathrm{dL}$ at baseline require significantly longer times to remission compared to patients with factor FVIII activity levels $\geq 1 \mathrm{IU} / \mathrm{dL}$ and may require combination IST rather than corticosteroids alone.

FVIII activity and inhibitor levels should be monitored at least weekly.

Apply individualized therapy according to the patient's general condition, underlying concomitant diseases, and prognostic factors (i.e., FVIII < $1 \mathrm{IU} / \mathrm{dL}$, inhibitor titer $>20 \mathrm{BU} / \mathrm{mL}$, presence of anti-FVIII-IgA, antibodies, etc.) when available

AHA: acquired hemophilia A; CR: complete remission; IST: immunosuppressive therapy; PO: orally; IV: intravenous.

aFew data available in AHA, but reports available in other autoimmune disorders.

Taken from Kruse-Jarres et al., $2017^{79}$

\section{Inhibitor eradication}

All adult patients with an established diagnosis of AHA should receive immunosuppressive therapy (IST) immediately, with objective of eliminating the cell clone responsible for the synthesis of autoantibodies. Table 23 describes recommended options and doses for first-line IST regimens, which should be individualized according to general conditions of patient, comorbidities, and risk factors. Patients with FVIII $<1 \%$ residual activity usually require longer treatment time and/or a combined TIS to obtain a response ${ }^{85}$.

\section{Relevant considerations for IST}

The most widely used IST regimen is prednisone as monotherapy (1-2 mg/kg/day for 4-6 weeks) or combination with cyclophosphamide (CP) for up to 5 weeks, either orally or parenterally (Table 23 ), with response rate between 70 and $80 \%$, with no significant difference in the average time to reach response. According to the EACH2 patient cohort registry, the combined use of steroid/CP resulted in a higher response rate of $70 \%$ versus $48 \%$ compared with prednisone as monotherapy, with no significant difference in overall survival, secondary to increased CP toxicity. Combined prednisone/CP therapy has been suggested for patients with inhibitor titers $>100 \mathrm{BU} / \mathrm{ml}$ and FVIII level $<1 \%$, or patients with autoimmune disorders ${ }^{92}$. The prospective study by Tiede et al. ${ }^{93}$ documented as independent predictive values of good prognosis patients with FVIII levels $>1 \%$ and inhibitor titers $<20$ $\mathrm{BU} / \mathrm{ml}$, suggesting less aggressive therapy and fewer side effects in this subgroup of patients.

Anti-CD20 monoclonal antibodies (rituximab) are reserved for those cases with an absolute contraindication for first-line drugs and/or as a second-line or relapse alternative. The response rate with rituximab regimens is similar to that obtained with steroid and/ or steroid/CP at $59 \%$. Even though, the response time with rituximab as monotherapy is longer than with other regimens (median 64 days), it has a lower relapse rate of $4 \%$ versus $14 \%$ and $19 \%$ with steroid/CP or steroid alone, respectively. The Cochrane review (2016) did not identify any controlled clinical trial that conclusively evaluates the use of rituximab in AHA and therefore suggests that the decision should be formulated according to larger observational studies with the least methodological bias possible ${ }^{94}$.

IV immunoglobulin (IVIg) alone or combination with steroids has not shown efficacy as first-line treatment in various studies. However, unlike congenital hemophilia, where ITI with high doses of FVIII is the adequate indication, Zeitler's study analyzed results in 60 
of 67 patients with AHA (mostly idiopathic) using modified Bonn-Malmö protocol, which combined immunoadsorption with high plasma volumes, IVIg, and immunosuppression with $\mathrm{CP} /$ prednisone and subsequent FVIII administration at a dose of $100 \mathrm{U} / \mathrm{kg}$ every 4-6 h, obtaining complete remission (FVIII $\geq 70 \%$ and undetectable inhibitor) in $91 \%$ in a median follow-up of 62 months $^{84}$. At the date of this publication, it is the only study in which immunotolerance is attempted as a therapeutic goal in AHA. Finally, due to the low incidence of AHA in pediatric population, the use of IST is controversial.

Patients who do not show an increase in FVIII levels after 3-5 weeks of treatment should be considered for second-line therapy. Second-line IST alternatives include calcineurin inhibitors such as cyclosporine (useful in AHA associated with lupus at doses of $10-15 \mathrm{mg} / \mathrm{kg}$ ) or tacrolimus; mycophenolate mofetil; multiple immunosuppressive and cytotoxic drugs (such as azathioprine, cladribine, and vincristine) ${ }^{85,87}$; or immunotolerance protocols, but provide scarce contribution from medical literature.

A retrospective study by Napolitano analyzed 105 cases of AHA associated with neoplasia, where the three most frequent solid tumors were prostate, lung, and colon (25.3\%, $15.8 \%$, and $9.5 \%$, respectively) and hematological malignancies: lymphoma $24.4 \%$, chronic lymphocytic leukemia $22.3 \%$, and plasma cell dyscrasias in $20 \%$. The best responses (complete or partial) with inhibitor eradication were obtained in patients with effective cancer treatment, either with chemotherapy or surgical treatment in $88.8 \%$, without any statistical difference reports between variables as sex, age, inhibitor titers, kind of cancer, and hemostatic therapy used. This review highlights the interaction between neoplastic cells and their ability to generate an autoimmune response by various mechanisms ${ }^{95}$.

\section{Prognosis}

Prognosis of patient with AHA relies on severity and location of bleeding manifestations, access to specific treatment (hemostatic and IST), and comorbidities. Overall mortality rate fluctuates between 9 and 33\%, depending on studies and publication date. Early deaths from hemorrhage occur in the $1^{\text {st }}$ week after diagnosis, rates between 3.2 and $9.1 \%$, while late deaths are associated with side effects of IST. Studies published after 2010 mortality associated to sepsis or infection were $12-16 \%^{90,93,96}$. Mortality of $\geq 20 \%$ has been described in people older than 65 years with some underlying malignancy ${ }^{97}$. There is no conclusive evidence regarding prognostic factors for response to treatment in patients with AHA. Some studies indicate that patients with a level of $\mathrm{FVIII}<1 \%$, inhibitor titer $\geq 20 \mathrm{BU} / \mathrm{ml}$, poor physical performance at diagnosis, and IgA-type autoantibodies anti-FVIII have a worse prognosis.

The inhibitor relapse rate is $12-18 \%$, mostly in the first 2 years; which depends on type of ITS used, along with a lower rate for rituximab therapies, as previously discussed. International recommendation for monitoring patient who has obtained complete remission (undetectable inhibitor $<0.6 \mathrm{BU} / \mathrm{ml}$ and FVIII $>50 \%$ ) is monitoring aPTT and FVIII monthly during the first 6 months, followed by every 2 or 3 months in the following semester and every 6 months thereafter. In patients with relapse, it has been described that $50 \%$ respond to the same initial therapy and a quarter of them will depend on steroids. About $30 \%$ of patients present spontaneous remission (disappearance of the autoantibody), generally in cases of AHA associated with pregnancy or drugs.

\section{AHA and pregnancy}

The incidence of AHA is 1 in 350,000 births $^{86}$. It is usually manifested in the first pregnancy and first 3 months postpartum, with clinical presentation similar to other patients with $\mathrm{AHA}$, but with an increased risk of uterine and/or vaginal bleeding. There is a latent risk of bleeding for the product due to the potential passage of autoantibodies through the transplacental route.

The inhibitor acquired postpartum disappears spontaneously in $60-100 \%$ of cases, in an average of 30 months; however, treatment should be started immediately once diagnosis is stabilized, because of the high risk of bleeding. Treatment with bypassing agents is similar to patients with AHA, IST is restricted to steroids at established doses, and cytotoxic agents such as CP are contraindicated. Only one center has reported the effectiveness of rituximab postpartum. Prognosis of AHA associated with pregnancy is favorable if diagnosed and treated on time, as well as low relapse rate in a second pregnancy.

\section{Acquired HB (AHB)}

Two cases of AHB have been reported, described as acquiring a HB phenotype with FIX factor levels 
between 5 and $12 \%$ after orthotopic liver transplant from donors with HB not previously diagnosed, and therefore not due to presence of autoantibodies, as it occurs in AHA. Unlike FVIII, which production occurs at various extrahepatic sites (spleen, kidney, and endothelium), FIX is synthesized exclusively in the liver, so inadvertent transmission of mild HB through liver transplantation should be considered in patients with bleeding and/or a coagulopathy with prolonged aPTT after transplant ${ }^{98,99}$.

\section{Funding}

The authors did not receive any funding for carrying out this article.

\section{Conflict of interests}

The authors declare that they have no conflicts of interest.

\section{Ethical disclosures}

Protection of human and animal subjects. The authors declare that no experiments were performed on humans or animals for this study.

Confidentiality of data. The authors declare that they have followed the protocols of their work center on the publication of patient data.

Right to privacy and informed consent. The authors declare that no patient data appear in this article.

\section{References}

1. Garcia-Chavez J, Majluf-Cruz A. Hemofilia. Gac Med Mex. 2013;149:308-321.

2. Rogaev El, Grigorenko AP, Moliaka YK, Faskhutdinova G, Goltsov A, Lahti A, et al. Genomic identification in the historical case of the Nicholas II royal family. Proc Natl Acad Sci U S A. 2009;106:5258-63.

3. Otto JC. An account of an hemorrhagic disposition existing in certain families. Clin Orthop Relat Res. 1996;328:4-6.

4. World Federation of Hemophilia. Report on the Annual Global Survey; 2019.

5. Swystun LL, James PD. Genetic Diagnosis in Hemophilia and von Willebrand disease. Blood Rev. 2017;31:47-56.

6. Zimmerman B, Valentino LA. Hemophilia: in review. Pediatr Rev. 2013; 34:289-95.

7. Miller CH, Benson J, Ellingsen D, Driggers J, Payne A, Kelly FM, et al. F8 and F9 mutations in US haemophilia patients: correlation with history of inhibitor and race/ethnicity. Haemophilia. 2012;18:375-82.

8. Mundo-Ayala JN, Jaloma-Cruz AR. Evaluación del patrón de inactivación del cromosoma $X$ en portadoras sintomáticas y mujeres con hemofilia. Gac Med Mex. 2008:144:171-4.

9. Blanchette V, Srivastava A. Definitions in hemophilia: resolved and unresolved issues. Semin Thromb Hemost. 2015;41:819-25.

10. Group NHC Guideline Working. Nordic Hemophilia Guidelines Authors Nordic Hemophilia Council Guideline Working Group; 2017.

11. World Federation of Hemophilia. Diagnóstico de La Hemofi Lia y Otros Trastornos de La Coagulación; 2010.

12. Srivastava A, Santagostino E, Dougall A, Weill A, Pierce GF. WFH guidelines for the management of hemophilia, $3^{\text {rd }}$ edition. Haemophilia. 2020;26:1-158.

13. World Federation of Hemophilia. Diagnóstico y Tratamiento de Inhibidores de Los Factores $8^{\text {th }}$ y $9^{\text {th }} ; 2004$
14. Duncan E, Collecutt M, Street A. Nijmegen-Bethesda Assay to Measure Factor 8th Inhibitors. In: Hemostasis: methods and Protocols, Methods in Molecular Biology. 2013; 992: 321-33.

15. Mantilla-Capacho J, Beltrán-Miranda CP, Jaloma-Cruz AR. Diagnóstico molecular en pacientes y portadoras de hemofilia A y B. Gac Med Mex 2005;141:69-71.

16. Saxena R, Ranjan R. Prenatal diagnosis of hemophilia A and B. J Mol Biol Mol Imaging 2014:1:1-6.

17. México IM del SS. Diagnóstico y Tratamiento Hemofilia A y B En Población Mayor de 16 Años Del Segundo y Tercer Nivel de Atención; 2017.

18. Aznar JA, Marco A, Jiménez-Yuste V, Fernández-Fontecha E, Pérez R, Soto I, Parra R, Moreno M, et al. Is on-demand treatment effective in patients with severe haemophilia? Haemophilia. 2012;18:738-42.

19. Gringeri A, Lundin B, Von Mackensen S, Mantovani L, Mannucci PM, ESPRIT Study Group. A randomized clinical trial of prophylaxis in children with hemophilia A (the ESPRIT study). J Thromb Haemost. 2011;9:700-10.

20. Instituto Mexicano del Seguro Social. Lineamientos Operativos Para La Atención Del Paciente Con Hemofilia En Servicio de Urgencias; 2012.

21. Auerswald G, Dolan G, Duffy A, Hermans C, Jiménez-Yuste V, Ljung R, et al. Pain and pain management in haemophilia. Blood Coagul Fibrinolysis. 2016;27:845-54.

22. Escobar MA, Brewer A, Caviglia H, Forsyth A, Jimenez-Yuste V, Laudenbach $\mathrm{L}$, et al. Recommendations on multidisciplinary management of elective surgery in people with haemophilia. Haemophilia. 2018;24:1-10.

23. Solimeno LP, Escobar MA, Krassova S, Seremetis S. Major and minor classifications for surgery in people with hemophilia: a literature review. Clin Appl Thromb. 2018;24:549-59.

24. Manco-Johnson MJ, Abshire TC, Shapiro AD, Riske B, Hacker MR, Kilcoyne R, et al. Prophylaxis versus episodic treatment to prevent joint disease in boys with severe hemophilia. N Engl J Med. 2007;357:535-44.

25. Iorio A, Marchesini E, Marcucci M, Stobart K, Chan AK. Clotting factor concentrates given to prevent bleeding and bleeding-related complications in people with hemophilia A or B. Cochrane Database Syst Rev. 2011;9:CD003429.

26. Richards M, Williams M, Chalmers E, et al. A United Kingdom haemophilia centre doctors' organization guideline approved by the British committee for standards in haematology: Guideline on the use of prophylactic factor VIII concentrate in children and adults with severe haemophilia A. Br J Haematol. 2010;149(4):498-507.

27. Carcao M, Srivastava A. Factor VIII/factor IX prophylaxis for severe hemophilia. Semin Hematol. 2016;53(1):3-9.

28. Oldenburg J. Optimal treatment strategies for hemophilia : achievements and limitations of current prophylactic regimens. Blood. 2015;125(13):20382045.

29. Manco-Johnson MJ, Kempton CL, Reding MT, et al. Randomized, controlled, parallel-group trial of routine prophylaxis vs. on-demand treatment with sucrose-formulated recombinant factor VIII in adults with severe hemophilia A (SPINART). J Thromb Haemost. 2013:11(6):1119-1127.

30. Gringeri A, Lundin B, Mackensen SVON, Mantovani L, Mannucci PM. A randomized clinical trial of prophylaxis in children with hemophilia $A$ (the ESPRIT Study). J Thromb Haemost. 2011;9:700-710.

31. Tagliaferri A, Feola G, Molinari AC, et al. Benefits of prophylaxis versus on-demand treatment in adolescents and adults with severe haemophilia A: The POTTER study. Thromb Haemost. 2015; 114(1):35-45.

32. Coppola A, Morfini M, Cimino E, Tufano A, Cerbone AM, Minno D. Currente and evolving features in the clinival management of haemophilia. Blood Transfus. 2014;12(3):s554-62.

33. Valentino LA. Considerations in individualizing prophylaxis in patients with haemophilia A. Haemophilia. 2014;(March):1-9.

34. Tagliaferri A, Franchini M, Coppola A, et al. Effects of secondary prophylaxis started in adolescent and adult haemophiliacs. 2008:945-951.

35. Verma SP, Dutta TK, Mahadevan S, et al. A randomized study of very low-dose factor VIII prophylaxis in severe haemophilia - A success story from a resource limited country. Haemophilia. 2016;22(3):342-348.

36. Ar MC, Vaide I, Berntorp E, Björkman S. Methods for individualising factor VIII dosing in prophylaxis. Eur J Haematol. 2014;93(S76):16-20.

37. Valentino LA. Considerations in individualizing prophylaxis in patients with haemophilia A. Haemophilia. 2014;20(5):607-615.

38. Fischer K, Konkle B, Broderick C, Kessler CM. Prophylaxis in real life scenarios. Haemophilia. 2014;20(Suppl. 4):106-13.

39. Berntorp E, Astermark J, Baghaei F, et al. Treatment of haemophilia A and B and von Willebrand's disease: Summary and conclusions of a systematic review as part of a Swedish health-technology assessment. Haemophilia. 2012;18(2):158-165.

40. Berntorp E, Shapiro AD. Modern haemophilia care. Lancet. 2012; 379:1447-56

41. Bertamino M, Riccardi F, Banov L, Svahn J, Molinari AC. Hemophilia Care in the Pediatric Age. J Clin Med. 2017;6(54):1-13.

42. Gianotten WL, Heijnen L. Haemophilia, aging and sexuality. Haemophilia. 2009;15(1):55-62.

43. Franchini M, Mannucci PM. Co-morbidities and quality of life in elderly persons with haemophilia. Br J Haematol. 2009;148(4):522-33. 
44. Wong TE, Majumdar S, Adams E, et al. Overweight and obesity in hemophilia: A systematic review of the literature. Am J Prev Med. 2011:41(6 SUPPL.4):S369-S375.

45. Witmer C, Young G. Factor VIII inhibitors in hemophilia A: Rationale and latest evidence. Ther Adv Hematol. 2013;4(1):59-72.

46. Coppola A, Santoro C, Tagliaferri A, Franchini M, Minno GDI. Understanding inhibitor development in haemophilia A : towards clinical prediction and prevention strategies. Haemophilia. 2010;16(Suppl. 1):13-9.

47. Margaglione M, Intrieri M. Genetic Risk Factors and Inhibitor Development in Hemophilia: What Is Known and Searching for the Unknown. Semin Thromb Hemost. 2018;44:509-516.

48. Kempton CL, White GC. How we treat a hemophilia A patient with a factor VIII inhibitor. Blood. 2009;113(1):11-17.

49. Garagiola I, Palla R, Peyvandi F. Risk factors for inhibitor development in severe hemophilia A. Thromb Res. 2018;168(May):20-27.

50. Peyvandi F, Garagiola I, Young G. The past and future of haemophilia: diagnosis, treatments, and its complications. Lancet. 2016;388:187-197.

51. Peyvandi F, Garagiola I. Product type and other environmental risk factors for inhibitor development in severe hemophilia A. Res Pract Thromb Haemost. 2018:1-8.

52. Gouw SC, Bom JG Van Der, Berg HM Van Den, Study C. Treatment-related risk factors of inhibitor development in previously untreated patients with hemophilia A : the CANAL cohort study. Blood. 2007; 109(11):4648-55.

53. Gouw SC, Van Den Berg HM, Fischer K, et al. Intensity of factor VIII treatment and inhibitor development in children with severe hemophilia A: The RODIN study. Blood. 2013;121(20):4046-4055.

54. Gouw SC, Medisch A, Universiteit C, Bom JG Van Der, Ljung R. FactorVIII Products and Inhibitor Development in Severe Hemophilia A. 2013;(January 2016)

55. Iorio A, Halimeh S, Holzhauer S, et al. Rate of inhibitor development in previously untreated hemophilia A patients treated with plasma-derived or recombinant factor VIII concentrates : a systematic review. J Thromb Haemost. 2010;8:1256-1265

56. Peyvandi F, Mannucci PM, Garagiola I, et al. A randomized trial of facto VIII and neutralizing antibodies in hemophilia A. N Engl J Med. 2016;374(21):2054-2064.

57. Fallon PG, Lavin M, O'Donnell JS. SIPPET: insights into factor VIII immunogenicity. J Thromb Haemost. 2018:16(1):36-38.

58. Rosendaal FR, Palla R, Garagiola I, Mannucci PM, Peyvandi F. Genetic risk stratification to reduce inhibitor development in the early treatment of hemophilia A: a SIPPET analysis. Blood. 2017;130(15):1757-1759.

59. Peyvandi F, Mannucci PM, Palla R, Rosendaal FR. SIPPET: methodology, analysis and generalizability. Haemophilia. 2017;23(3):353-361.

60. Peyvandi F, Cannavò A, Garagiola I, et al. Timing and severity of inhibitor development in recombinant versus plasma-derived factor VIII concentrates: a SIPPET analysis. J Thromb Haemost. 2018;16(1):3943.

61. Holme PA, Tjønnfjord GE, Batorova A. Continuous infusion of coagulation factor concentrates during intensive treatment. Haemophilia. 2018;24:24-32

62. The Association of Hemophilia Clinical Directors of Canada. A Guide to the Management of Patients with Inhibitors to Factor VIII and Factor IX. 2010.

63. Astermark J, Donfield SM, Dimichele DM, Gringeri A, Gilbert SA, Waters $\mathrm{J}$. A randomized comparison of bypassing agents in hemophilia complicated by an inhibitor : the FEIBA NovoSeven Comparative (FENOC) Study. Blood. 2007;109(2):546-551

64. Qi X, Zhao Y, Li K, Fan L, Hua B. Evaluating and monitoring the efficacy of recombinant activated factor VIla in patients with haemophilia and inhibitors. Blood Coagul Fibrinolysis. 2014;25:754-760

65. Fernández-Bello I, Stenmo C, Butta N, Lind V, Ezban M, Jiménez-Yuste $V$. The pharmacokinetics and pharmacodynamics of single- dose dose recombinant activated factor VII in patients with haemophilia A or B. Haemophilia. 2017:1-9.

66. Schep SJ, Schutgens REG, Fischer K, Boes ML. Review of immune tolerance induction in hemophilia A. Blood Rev. 2018;32(4):326-338.

67. Giangrande PLF, Hermans C, Mahony BO, et al. European principles of inhibitor management in patients with haemophilia. Orphanet J Rare Dis. 2018;13(66):1-6.

68. Brackmann HH, Gormsen J. Massive Factor-VIII infusion in hemophiliac with factor-VIII inhibitors, high responder. Lancet. 1977:933.

69. Carcao M, Escuriola C, Elena E, et al. The changing face of immune tolerance induction in haemophilia $\mathrm{A}$ with the advent of emicizumab. Haemophilia. 2019;00:1-9.

70. Brackmann H-H, White GC, Berntorp E, Andersen T, Escuriola-Ettingshaussen $\mathrm{C}$. Immune tolerance induction: What have we learned over time ? Haemophilia. 2018;24(Suppl.3):3-14.
71. Ljung R, Auerswald G, Benson G, et al. Inhibitors in haemophilia A and $B$ : Management of bleeds, inhibitor eradication and strategies for difficult $\square$ to $\square$ treat patients. Eur J Haematol. 2019;102:111-122.

72. Hay CRM, Dimichele DM, Immune I, Study T. The principal results of the International Immune Tolerance Study: a randomized dose comparison. Blood. 2012;119(6):1335-1345.

73. Tencer T, Friedman HS, Li-McLeod J, Johnson K. Medical Costs and Resource Utilization for Hemophilia Patients With and Without HIV or HCV Infection. J Manag care Pharm. 2007;13(9):790-798.

74. Wyseure T, Mosnier LO, von Drygalski A. Advances and Challenges in Hemophilic Arthropathy. Semin Hematol. 2017;53(1):10-19.

75. Neme D. Tratamientos en hemofilia: ¿algo más que concentrados y factor VII recombinante activado? Hematologica. 2016;20:185-188.

76. Arruda VR, Doshi BS, Samelson-jones BJ. Emerging therapies for hemophilia: controversies and unanswered questions[version 1; referees: 4 approved]. F1000Research. 2018;7(0):1-13

77. Hartmann J, Croteau SE. 2017 Clinical trials update : Innovations in hemophilia therapy. Am J Hematol. 2017;91(12):1252-1260.

78. Tiede A. Half-life extended factor VIII for the treatment of hemophilia A J Thromb Haemost. 2015;13(Suppl. 1):S176-S179.

79. Franchini M, Mannucci PM. Non-factor replecement therapy for haemophilia: a current update. Blood Transfus. 2018:16:457-461.

80. Arruda VR, Doshi BS, Samelson-jones BJ. Novel approaches to hemophilia therapy : successes and challenges. Blood. 2017;130(21):22512256.

81. Oldenburg J, Mahlangu JN, Kim B, et al. Emicizumab Prophylaxis in Hemophilia A with Inhibitors. N Engl J Med. 2017;377:809-818.

82. Pipe SW, Shima M, Lehle M, et al. Efficacy, safety, and pharmacokinetics of emicizumab prophylaxis given every 4 weeks in people with haemophilia A (HAVEN 4): a multicentre, open-label, non-randomised phase 3 study. Lancet Haematol. 2019;3026:1-11.

83. Ohmori T. Advances in gene therapy for hemophilia : basis, current status, and future perspectives. Int J Hematol. 2018;111(1):31-41.

84. Franchini M, Vaglio S, Marano G, et al. Acquired hemophilia A : a review of recent data and new therapeutic options. Hematologica. 2017; 22(9):514-520.

85. Kruse-Jarres R, Kempton CL, Baudo F, et al. Acquired hemophilia A: Updated review of evidence and treatment guidance. Am J Hematol. 2017;92:695-705

86. Charlebois J, Rivard G-étienne, St-louis J. Management of acquired hemophilia A : Review of current evidence. Transfus Apher Sci. 2018:1-4.

87. García-Chávez J, Majluf-Cruz A. Hemofilia adquirida. Gac Med Mex. 2020;156(1):67-77

88. Mingot-castellano ME, Nú R. Hemofilia Adquirida: epidemiología, clínica, diagnóstico y tratamiento. Med Clin (Barc). 2017:1-9.

89. Huth-Kühne A, Baudo F, Collins $\mathrm{P}$, et al. International recommendations on the diagnosis and treatment of patients with Acquired hemophilia a. Haematologica. 2009;94(4):566-575.

90. Knoebl P, Marco P, Baudo F, et al. Demographic and clinical data in acquired hemophilia A: Results from the European Acquired Haemophilia Registry (EACH2). J Thromb Haemost. 2012;10(4):622-631.

91. Zanon E, Milan M, Gamba G, et al. Activated prothrombin complex concentrate (FEIBA $\Theta)$ for the treatment and prevention of bleeding in patients with acquired haemophilia: A sequential study. Thromb Res. 2015;136(6):1299-1302.

92. Ceresetto JM, Duboscq C, Fondevila C, Pinto MT. HEMOFILIA ADQUIRIDA (INHIBIDOR ADQUIRIDO DEL FACTOR VIII) Cuadro clínico. Medicina (B Aires). 2015;75:231-238.

93. Tiede A, Klamroth R, Scharf RE, et al. Prognostic factors for remission of and survival in acquired hemophilia $\mathrm{A}(\mathrm{AHA})$ : Results from the GTHAH 01/2010 study. Blood. 2015;125(7):1091-1097.

94. Zeng Y, Zhou R, Duan X, Long D. Rituximab for Eradicating Inhibitors in People with Acquired Haemophilia A.; 2016.

95. Napolitano M, Siragusa S, Mancuso S, Kessler CM. Acquired haemophilia in cancer : A systematic and critical literature review. Haemophilia. 2017:1-14.

96. Calvez T, Chambost H, Oiron R, et al. Analyses of the FranceCoag cohort support immunogenicity differences among one plasma-derived and two recombinant factor VIII brands in boys with severe hemophilia A. 2017.

97. Delgado J. Acquired haemophilia: review and meta-analysis focused on therapy and prognostic factors. Br J Haematol. 2003;121:21-35.

98. Bergstrom K, Stevens A, L S, J E, DL Y. Haemophilia B acquired from liver transplantation : a case report and literature review. Haemophilia. 2015;21:e328-e329

99. Brunetta D, Carneiro-Silva F, Marinho V J, et al. Through Liver Transplantation. Liver Transplant. 2016;22:256-256. Hemophilia B Acquired 